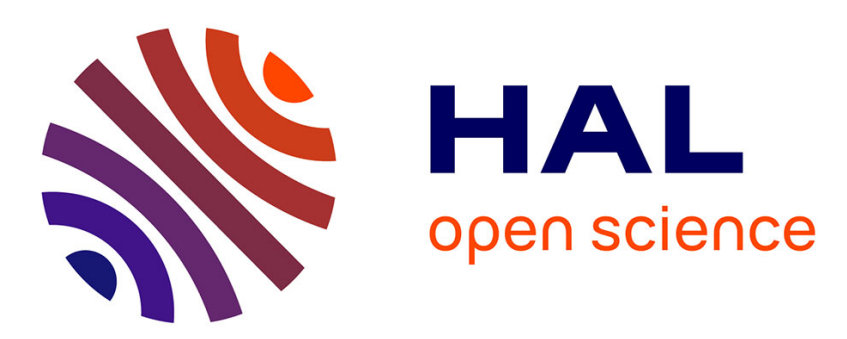

\title{
Home health-care network design: Location and configuration of home health-care centers
}

Carlos Rodriguez-Verjan, Vincent Augusto, Xiaolan Xie

\section{To cite this version:}

Carlos Rodriguez-Verjan, Vincent Augusto, Xiaolan Xie. Home health-care network design: Location and configuration of home health-care centers. Operations Research for Health Care, 2017, 10.1016/j.orhc.2017.09.001 . hal-01623131

\section{HAL Id: hal-01623131 \\ https://hal.science/hal-01623131}

Submitted on 25 Oct 2017

HAL is a multi-disciplinary open access archive for the deposit and dissemination of scientific research documents, whether they are published or not. The documents may come from teaching and research institutions in France or abroad, or from public or private research centers.
L'archive ouverte pluridisciplinaire $\mathbf{H A L}$, est destinée au dépôt et à la diffusion de documents scientifiques de niveau recherche, publiés ou non, émanant des établissements d'enseignement et de recherche français ou étrangers, des laboratoires publics ou privés. 


\title{
Home Health-Care Network Design: Location and Configuration of Home Health-Care Centers
}

\author{
Carlos Rodriguez-Verjan, Vincent Augusto and Xiaolan Xie \\ UMR CNRS 6158 LIMOS, \\ Center for Biomedical and Health-care Engineering, \\ École Nationale Supérieure des Mines de Saint-Étienne \\ 158 cours Fauriel 42023 Saint-Étienne cedex 2, France
}

January 2017

\begin{abstract}
Home Health-Care (HHC) is a concept slowly expanding over time, introduced to reduce pressure on inpatient hospital beds by providing care to patients at home. Nowadays, HHC centers are able to undertake more technical complex care such as (but not limited to) endof-life care, chemotherapy and rehabilitation. This article accomplishes two main objectives: (i) design a home health-care network by locating HHC centers across a territory, taking into account medical demand and costs of resources and facilities; (ii) optimally manage the activities of HHC centers by deciding on the outsourcing of critical processes for patient care. Two mixed-integer linear programs are proposed to solve these problems and propose strategic and tactical decisions. A practical case study is proposed on the Loire department (France) with various scenarios to test the robustness of the model depending on demand variation. The proposed method gives efficient plans for designing and managing HHC centers with cost-efficient solutions on both strategic and tactical level.
\end{abstract}

Keywords: Home health-care; location; allocation; cost analysis; resource management; strategic design; optimization

\section{Introduction}

Health-care systems efficiency optimization is beyond the scope of the hospital. The challenges of the twentieth century aim to connect health facilities in order to better understand and accompany patient's pathway throughout their care process on the long term. Health-care centers are now designed to collaborate within a network, and this requires a rigorous organization. Besides the quality of care provided to the patient, reducing costs remains a primary goal of health systems. Deficit of hospitals in most of European countries is an incentive to find new measures to cure "better" and "cheaper". Indeed, an ever aging population imposes health professionals a continuously increasing workload, even if resources are constant. Efficient health-care network organizations supported by modern information technology infrastructure can help solve this challenge.

Home Health-Care (HHC) is an important organization of health-care in developed countries, allowing patients to be treated at home when possible. Such approach is cost-efficient Rodríguez-Verjan et al., 2012 if the HHC centers are wisely organized in a network, allowing traditional hospitals to free beds for acute care and avoid bed-blockers. Experiences of hospitalization at home are not so numerous. Technical care (such as chemotherapy, blood transfusion, 
rehabilitation...), once devoted to hospital, might now be dispensed at home Shepperd et al., 2009], but experiences remained local and isolated. Moreover, HHC centers usually have a fragile economic model, dependent on the characteristics of the local territory (type of population, type of demand, proximity with hospitals). It is difficult to establish economic viability of such facilities Rischin et al., 2000, Goulet et al., 2001, Chataway et al., 2006]. Nevertheless, patient satisfaction is usually higher when admitted in HHC [Borras et al., 2001].

In this context it seems reasonable to design a home health-care network by taking into account the whole health-care landscape of the territory. Nowadays, no regional strategy is provided for the design and the control of home health-care networks although taking into account the adjustment between demand, resources and location seems crucial. To do so, the development of strategic and tactical decision aid tools is a good solution to optimize the location and demand allocation of HHC centers on a territory.

In this paper, we propose a new methodology for the design and economic viability assessment of home health-care centers on the regional level. Taking into account crucial health characteristics of a territory, we propose a comprehensive optimization model for designing a strategic plan for home health-care network through a net of centers working in collaboration, taking into account medical demand, cost of resources and activity balance between practitioners. An economic assessment of home health-care centers is also provided, taking into account the management of the operations of health-care activities on the tactical level. Such approach constitutes a rich scientific contribution since the provided literature review does not provide any model for the home health-care network organization.

The article is organized as follows. A literature review on home health-care organization optimization and evaluation is provided in Section 2. The proposed methodology for the strategic design of a HHC network and for the tactical management of HHC centers is detailed in Section 3 . The first problem related to strategic HHC center location is described in Section 4. The second problem related to the tactical management of HHC activities is described in Section 5 . Application to a real case study is provided in Section 6. Finally, conclusions and perspectives are developed in Section 7 .

\section{Literature review}

Although HHC is developing in various countries due to the aforementioned increasing hospitalization costs coupled with an aging population, it benefits from little published researched in comparison to classical health-care problems such as nurse rostering problem, operating rooms planning or hospital resource sizing. HHC organization is different from one country to another, as shown by the comparative work of [Chevreul et al., 2005]. In France, there is an important distinction between hospitalization at home and nursing at home, whereas other countries may only have low level of home care (United Kingdom), only HHC (Australia), or both types with a less clear distinction (Canada). Most obvious problems related to home health-care are connected to vehicle routing problem and human resource scheduling problem. Yalcindag et al. 2011] proposed a literature review on the topic. Most of these articles address the issue of finding the optimal way to treat the admitted patients.

Most of work related to the location of health-care centers are based on the covering problem. A comprehensive state of the art of location studies applied to the public sector is provided by Marianov and Serra 2001. Preliminary studies Toregas et al. 1971, Garey and Johnson, 1979 intends to locate health-care centers using an extension of the set covering problem. A literature review on algorithms used to solve the set covering problem can be found in Caprara et al. [2000]. The maximum covering problem has also been extended for health-care in various situations. Eaton et al. 1985] propose a study to design an emergency network. A maximum covering model is used to evaluate various policies for the organization of emergency services. 
Authors demonstrate that the method allows savings and reduces response time. In [Jia et al., 2007], authors define new concepts such as covering quantity and quality. Three solving methods are proposed, based on genetic algorithms, heuristics and Lagrangian relaxation. Finally, the literature related to ambulance location is rich. A state of the art is presented in Brotcorne et al. 2003 where authors define three types of problems: (i) deterministic (no random factors), (ii) stochastic, and (iii) dynamic (re-location of ambulances over the planning horizon). In this paper, we propose a new approach to locate HHC centers while maximizing the coverage or the expected coverage.

The tactical management of HHC centers has also received little attention in the literature. In Drake and Davies, 2006 authors proposed a review of relevant literature on the outsourcing of home care and its political drivers in the UK. Research has focused on Wales in general plus a few local authorities in England. Some works related to outsourcing in health-care are available. In Nicholson et al., 2004], authors address the issue of managing inventory costs in a health-care setting and compare an in-house three-echelon distribution network vs an outsourced two-echelon distribution network using two scenarios. Authors conclude that outsourcing does not compromise the quality of care and allows inventory cost savings. In Dalton and Warren, 2016], authors model outsourcing as trade-off of income vs control over production and discuss differences between the two approaches. Difference is not significant with fixed cost shocks. An extension of the model of nonprofit entrepreneurship Glaeser and Shleifer, 2001 is proposed to include an outsourcing decision. In [Mariani et al. 2014], authors propose a representation of the current state of outsourcing in the Italian Healthcare System by focusing on satisfaction level of operators involved in outsourcing. Results show mixed satisfaction level depending on the status of the operator. Several studies are also related to the outsourcing of various component of health-care systems such as information systems Lorence and Spink, 2004 or other very special activities within hospitals such as waste disposal processes or logistics. In this paper, we propose a methodological guide to help HHC managers to decide on the precise outsourcing of their operational process using exact optimization and extensive design of experiment approaches.

To the best of our knowledge, the strategic conception of a HHC network and its economical resource management has not been yet addressed in the literature. Most related papers refer to staff dimensioning in HHC Rodríguez-Verjan et al., 2015] where stochastic demands were taken into account. The network configuration was analyzed in Benzarti et al. 2013 by proposing solutions for the districting problem. The closest work related to the present article is presented in [Matta et al., 2014] where authors proposed a comprehensive approach to optimize the organization of home health-care centers. In this paper, we propose a new comprehensive methodology for two different stake holders: (i) high level decision maker (regional health agencies), by providing solutions for the strategic HHC location problem aiming at maximizing the covering of demand while taking into account traditional hospitalization; (ii) HHC center manager, by providing a cost-effective approach for the management of human resources in a HHC center once its location has been decided through a set of design of experiments.

\section{Methodology for home health-care network design}

The home health-care (HHC) strategic location problem and tactical configuration problem tackled in this paper consist in providing an efficient coverage over a territory for the medical demand, i.e. patients requiring medical care at home for various pathologies. The territory under consideration is composed of zones. For each zone, a demand is evaluated, corresponding to a number of patients suffering from a certain type of pathology. In this paper, activities performed by HHC centers are exclusively related to home care (such as visits to patients); patients are not supposed to travel to HHC centers. However, if HHC centers are unable to satisfy the demand for home care, these patients will be treated in traditional hospitals. Taking into account the 
characteristics of the territory such as the capacity of hospitals and the possible locations for HHC centers, the proposed methodology consists in answering the following research questions: (i) Where should HHC centers be located across the territory? (ii) What are the resources needs (number and type of different resources) required to satify demand over a certain time horizon and across the territory? (iii) How should the management of activities (e.g. services provided) of each center be controlled?

Figure 1 illustrates the problem with the case study of the Loire department (France). In this example, the territory is divided into four demand zones, each zone having a certain demand for care depending on pathologies $\left(P_{1}, P_{2}, P_{3}\right)$. Several locations (red squares) are available for the opening of new HHC centers to satisfy the demand, each center having a certain number of resources available to visit patients at home (nurses, doctors, specialists). Finally, each HHC center may be managed in a different way and may choose to outsource its activities or not to ensure its economic viability.

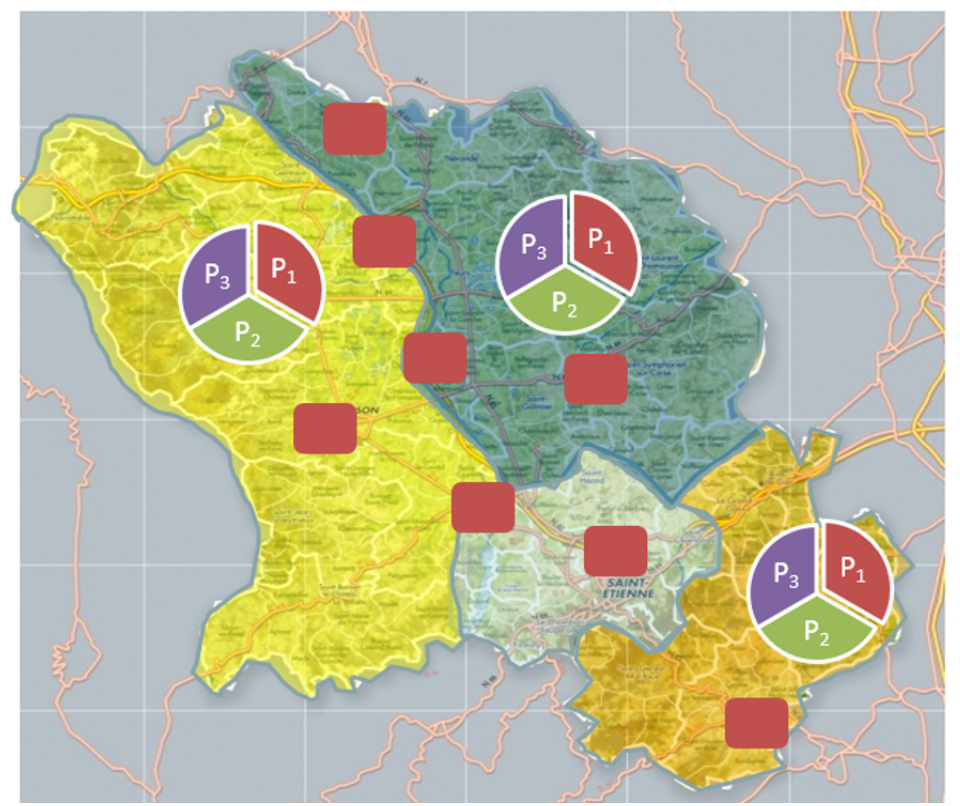

Figure 1: Home health-care network design example

The proposed methodology intends to design and optimize the HHC centers configuration across a territory in two steps:

1. Strategic design the HHC network. Taking into account the characteristics of the territory, a Mixed-Integer Linear Programming (MILP) model is provided to design the HHC network by deciding the location of centers, the composition of medical teams, and the assignment of demand. Collaboration between centers and hospitals is taken into account in this approach through the allocation of demand (Section 4).

2. Tactical management of each HHC center. Once the network has been designed, another MILP model is provided to determine the organization and the management of each center, taking into account the subset of demand assigned to it, in order to ensure economic viability. As a result we propose a decision aid tool for HHC managers taking into account the opportunity of outsourcing activities (Section 5).

The proposed approach is applied to design the HHC network on both strategic and tactical level. The methodology has been applied on various scenarios in order to take into account 
the sensitivity of results against input data. Such experiment is provided in the case study in Section 6. A software has been implemented and extensively tested using real data.

The main contribution of the paper is a methodology that can be used by stakeholders such as HAH centers managers, but also health authorities such as regional health agencies. Purposes of proposed models are very different: (i) the HHC multi-period location problem has been designed for health authorities, and intends to define a strategic plan for health services deployment across a large territory and over a long time horizon, whereas (ii) the tactical management of HHC activities problem has been designed for HHC centers managers to be used on a shorter time horizon to ensure that each center adapt itself to the evolving market. The scope is very different for each problem: several years for the first ones, whereas the second one might be ran on demand depending on the dynamic of the territory. Another contribution lies in the design of a decision aid software for regional health agencies and HHC centers managers.

\section{The strategic home health-care multi-period location problem}

\subsection{Problem description}

The HHC center location problem can be modeled as an extension of a multi-resources, multifacilities location problem. In this paper, HHC centers must be set on a territory to satisfy efficiently the demand. Opening centers and employing human resources decisions cannot be taken without considering special constraints such as: (i) care delivery authorization for certain pathologies (such authorization are delivered by health authorities and must be renewed periodically); (ii) medical human resources requirements (e.g. for delivering chemotherapy at home, at least a doctor and a nurse are required); (iii) demand evolution over time.

We consider a set of pathologies to be treated at home indexed by $p \in P$. Resources $r \in R$ are required to treat the patients at home depending of their illness. Time horizon is discretized in time periods $t \in T$. Before stating the model, the following assumptions are made:

Assumption 1 (Demand) The territory is divided into $\bar{J}$ demand zones. For each zone $j$, pathology $p$ and time period $t$, we define a demand quantity $\delta_{j p t}$ modeling the number of patients requiring home care.

Assumption 2 (Resource requirements) Each pathology is linked with a resource requirement $\tau_{p r}$ (number of units of resource $r$ required to satisfy one unit of demand of pathology $p$ in a time period).

Example 1 Let us consider a small example with a territory having only one demand zone, one pathology and two time periods. Ten patients in this demand zone $j=1$ are suffering from breast cancer $(p=1)$ in period 1; an increase is expected for period 2 with 15 patients. They may receive a chemotherapy at home; such treatment requires ten visits per month from one doctor $(r=1)$ and one nurse $(r=2)$. The doctor stays 15 minutes and the nurse stays 1 hour for each visit. In that example the demand quantity is defined as follows: $\delta_{1,1,1}=10$ and $\delta_{1,1,2}=15$; resources needs are $\delta_{1,1,1} \times \tau_{1,1}=10 \times 150$ and $\delta_{1,1,2} \times \tau_{1,2}=15 \times 600$ for time periods 1 and 2 .

Assumption 3 (Authorization) Each pathology p requires a special authorization. Each authorization has a fixed cost $\gamma_{p}$ and requires the employment of a minimal amount of human resources $\eta_{p r}$. Authorizations are given for a limited duration $\alpha$ and should be renewed. In France, an authorization to deliver care at home is delivered by the local regional health agency and lasts five years. It is a legal requirement for every HHC center and allow health authorities to control and regulate the amount of home care delivered across the territory. It also ensures a certain level of quality of care through the minimal amount of human resources required. 
Assumption 4 (Unsatisfied demand penalty) If a demand is unassigned, a penalty cost $c_{p}$ is raised to model the negative impact on traditional hospitalization: each patient not treated by HHC must be hospitalized, which should be avoided.

Assumptions 3 and 4 are introduced in the model to best balance the ratio of patients treated at home versus patients treated in traditional hospitals. Cost adjustment is important and will be studied in the following through design of experiments.

Assumption 5 (Resources) Only human resources are considered in this study. Each resource has a capacity in terms of number of care actions $q_{r} s /$ he can deliver, also denoted resource capacity or maximum load.

Assumption 6 (Costs) Costs are related to possible decisions. Opening a center in location $i$ has a fixed cost $f_{i}$. Assigning resources has a cost related to demand and distance: traveling duration between demand zones and the main HHC facility represent an important cost. Such argument has been confirmed in [Triki et al., 2014]. Finally, each resource has a variable cost $a_{r}$ (salary) and a fixed cost $a_{r}^{+}$(resp. $a_{r}^{-}$) related to his/her employment (resp. departure).

Example 2 (Traveling distance) Let us consider a doctor from HHC center $i$ visiting a patient in demand zone $j$ (traveling duration $d_{i j}=30$ minutes). Let us assume work load of doctor related to the traveling distance is $\xi_{r}=10 \%$. In that case, resource requirement considering the distance is $\xi_{r} \times d_{i j}=33$ minutes.

Assumption 7 (Single sourcing) Each demand $(p, j)$ is satisfied by at most one center. Demand zones have been defined by health authorities to be served by a sole health-care provider. This is why we actually consider a high number of demand zones in the case study.

\subsection{Formal model}

The MILP model for the HHC location problem is defined as follows.

Indexes and sets:

- $T$ : set of time periods, indexed by $t$.

- $P$ : set of pathologies, indexed by $p$.

- $R$ : set of resources, indexed by $r$.

- $J$ : set of demand zones, indexed by $j$.

- $I$ : set of possible locations for centers, indexed by $i$.

Parameters:

- $\delta_{j p}$ : demand for pathology $p$ in demand zone $j$.

- $q_{r}$ : resource capacity (maximum load) of resource $r$.

- $\xi_{r}$ : work load of resource $r$ related to the distance between center and patients, depending on resource type.

- $\tau_{p r}$ : work load of resource $r$ to give care for a patient suffering from pathology $p$. Hence, taking care of patient $p$ in zone $j$ by center $i$ has a total work load $\tau_{p r}+\xi_{r} d_{i j}$ for resource $r$. 
- $\eta_{p r}$ : minimal amount of resource $r$ required to get authorization for pathology $p$.

- $d_{i j}$ : distance between center location $i$ and demand zone $j$.

- $f_{i}$ : fixed cost for opening a center in location $i$.

- $c_{p}$ : penalty cost for not serving pathology $p$.

- $\gamma_{p}$ : authorization cost for serving pathology $p$.

- $a_{r}$ : variable cost (salary) for resource $r$.

- $a_{r}^{+}$(resp. $a_{r}^{-}$): fixed cost to increase (resp. decrease) a resource quantity.

Decision variables:

- $Y_{i t}=1$ if center $i$ is opened at time period $t$.

- $X_{j p i t}=1$ if demand type $p$ of demand zone $j$ is served by center $i$ at time period $t$.

- $Z_{i p t}=1$ if center $i$ is authorized to serve demand type $p$ at time period $t$.

- $N_{\text {irt }}$ : amount of resources $r$ to employ in center $i$ at time period $t$.

- $Q_{i r t}^{+}\left(\right.$resp. $\left.Q_{i r t}^{-}\right)$: number of resource units of type $r$ increased (resp. decreased) at the beginning of period $t$ in center $i$.

Costs definition:

- $\sum_{i t} f_{i} Y_{i t}$ : opening cost of centers (cost related to the acquisition of a building and materials in chosen locations over the time horizon).

- $\sum_{p j i t} \delta_{j p} d_{i j} X_{j p i t}$ : demand assignment cost (cost related to the distance between the assigned resource and the demand zone for all centers over the time horizon).

- $\sum_{i r t} a_{r} N_{i r t}$ : total resource cost (cost related to the salary of all practitioners employed in all centers over the time horizon).

- $\sum_{i, r, t}\left(a_{r}^{+} Q_{i r t}^{+}+a_{r}^{-} Q_{i r t}^{-}\right)$: total cost over the time horizon to increase or decrease resource quantities (e.g. base amount paid by a center to employ or dismiss a physician).

- $\sum_{i p t} \gamma_{p} Z_{i p t}$ : authorization cost (amount paid by all centers for serving a certain pathology over the time horizon).

- $\sum_{p j t} c_{p} \delta_{j p}\left(1-\sum_{i} X_{j p i t}\right):$ penalty cost (amount paid for not serving certain demand zones over the time horizon). 
The mathematical problem is defined as follows:

$$
\begin{array}{r}
\min \sum_{i, t} f_{i} Y_{i, t}+\sum_{t, p, j, i} \delta_{j p t} d_{i j} X_{j p i t} \\
+\sum_{t, i, r} a_{r} N_{i r t}+\sum_{i, r, t}\left(a_{r}^{+} Q_{i r t}^{+}+a_{r}^{-} Q_{i r t}^{-}\right) \\
+\sum_{t, i, p} \gamma_{p} Z_{i p t}+\sum_{t, p, j} c_{p} \delta_{j p t}\left(1-\sum_{i} X_{j p i t}\right)
\end{array}
$$

s.t.

$$
\begin{aligned}
\sum_{p, j}\left(\tau_{p r}+\xi_{r} d_{i j}\right) \delta_{j p t} X_{j p i t} \leqslant N_{i r t} q_{r} & \forall i, r, t \\
\sum_{i} X_{j p i t} \leqslant 1 & \forall j, p, t \\
\sum_{j} X_{j p i t} \leqslant \sum_{t^{\prime \prime}=t-\alpha}^{t} Z_{i p t^{\prime \prime}} & \forall p, i, t \\
Z_{i p t} \leqslant Y_{i t} & \forall i, p, t \\
\eta_{p r \sum_{t^{\prime \prime}=t-\alpha}^{t} Z_{i p t^{\prime \prime}} \leqslant N_{i r t}} & \forall p, i, t, r \\
Y_{i t} \leqslant Y_{i, t+1} & \forall i, t \\
N_{i r t}=N_{i r t-1}+Q_{i r t}^{+}-Q_{i r t}^{-} & \forall i, r, t \\
Y_{i t}, Z_{i p t}, X_{j p i t} \in\{0,1\} & \forall i, t \\
N_{i r t}, Q_{i r t}^{+}, Q_{i r t}^{-} \in \mathbb{N}^{*} & \forall r, i, t
\end{aligned}
$$

The first part of the objective function (1) is the sum of fixed costs related to the centers and the authorizations. The second part (2) is related to the variable and fixed costs of resources. The third part (3) models assignment costs and demand penalties.

Constraints set (4) is the capacity constraint. Constraints set (5) assigns a pathology of a demand zone to at most one center. Constraints set (6) forces to get the authorization when a demand is assigned. Constraints set (7) ensures no authorization can be given if the center is not opened. Constraints set (8) ensures the minimum quantity of resources is respected when an authorization is given. Constraints set (9) ensures opened centers cannot be closed. Constraints set (10) is the definition of the resources amount in the centers. Finally, constraints sets (11) and (12) defines the type of variables (binary and integer).

This problem is NP-hard, meaning it cannot be solve in polynomial time: if only one period is considered and if authorization costs, resource costs and penalty costs are set to zero, the well-known location-assignment problem appears, which is itself NP-hard Garey and Johnson, 1979|. In this problem, we take decisions for the location of centers and the timing of their opening at the same time. It constitutes a scientific challenge because the complexity of the problem might be an obstacle depending on the scenario under study. As shown in the model performance analysis in the following, we observe that bigger instances cannot be solved to optimality within reasonable time.

In this problem, the opening of a HHC center on a possible location is possible anytime over the time horizon, however it is indeed impossible to close a center. This constraint has been added to ensure that centers are not opened for a short amount of time since some pathologies 
are characterized by a quick variation of the demand over time. Also, social constraints are important: human resources should not be dismissed shortly after employment and center opening. The goal does not consist only in deciding on HHC centers location, but also in determining the best timing of their opening over the time horizon, and the best adjustment of overall health resources of the territory considering collaboration.

\subsection{Model performance analysis}

In this section we propose theoretical numerical tests to assess the performance of the model presented in the previous section. Random data sets are generated taking into account the real case study. Necessary information (volume of demand, pathologies, availability of resources, costs) have been extracted from relevant public databases. We generate demand zones located around main cities of the territory, as presented in Figure 3. The Loire department is presented in Figure 2. Demand zones have been randomly generated in an orthogonal coordinate system in order to easily calculate distances between zones and centers possible locations. Coordinates and distances are expressed in kilometers. Origin of the system has been randomly chosen centered on the Saint-Bonnet-le-Château city. Negative coordinates are not a problem in that case. Thirty data sets have been randomly generated for each scenario, using the intervals proposed in Table 1. Bounds of the intervals have been estimated with the help of health economists. Uniform distributions are used for all varying parameters. Distances have been calculated using the Floyd-Warshall algorithm Floyd, 1962 to guarantee a geographical coherence.

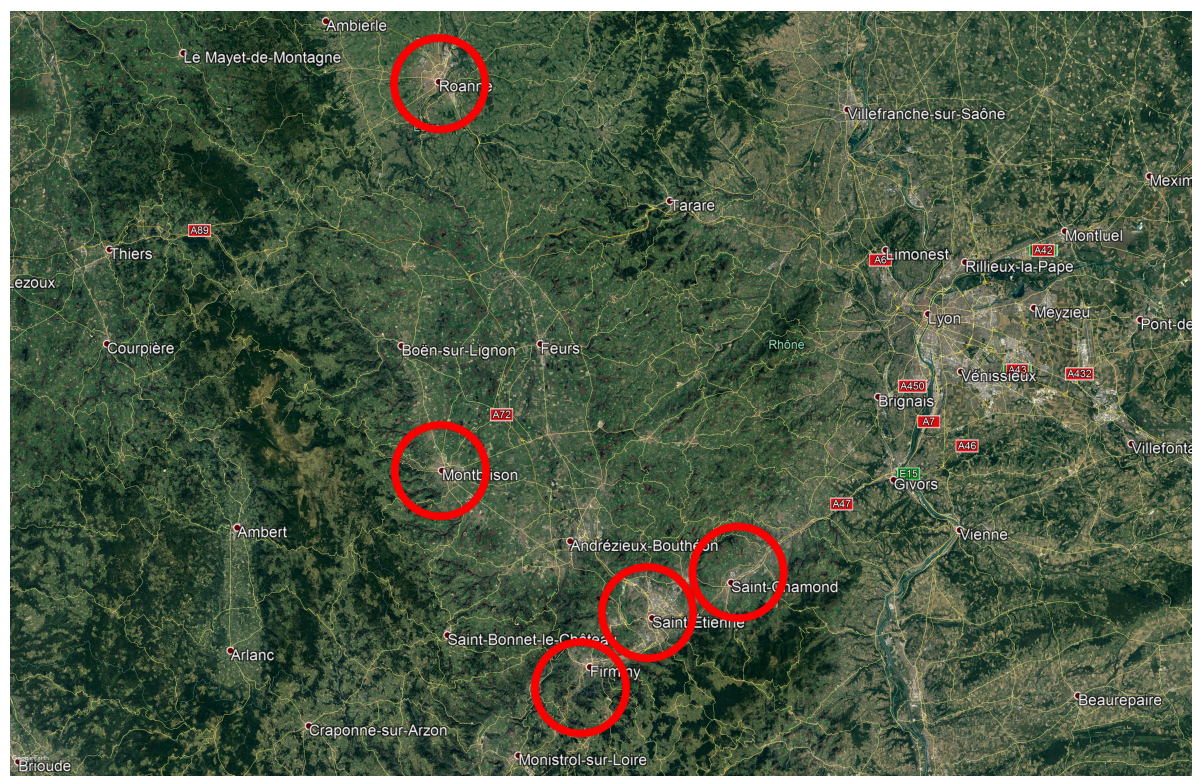

Figure 2: Map of the Loire department with its five main demand centers

Numerical tests have been performed using IBM ILOG CPLEX 12.0 on a computer with an Intel Dual-Core 2.2Ghz CPU. Scenarios and results are presented in Table 2. Configuration a.b.c.d.e means $a$ possible locations, $b$ demand zones, $c$ pathologies, $d$ resource types and $e$ time periods. Optimization is stopped when either a gap limit $(0.5 \%, 0.1 \%$ and $0.05 \%)$ or a time limit for the biggest instances (900 seconds) is reached. Average computational times are provided in the fourth column. Average final gaps are given in the fifth column. The last column indicates the ratio of instances for which the calculation was stopped due to the time limit.

Finding a solution with a gap lower than $1 \%$ is fast, but reaching an optimal solution may be long, especially for data sets IV and V. Computational time is highly impacted by the amount of demand zones and potential locations for HHC centers. For multi-period scenarios (VI-VII), 


\begin{tabular}{|c|l|l|}
\hline Parameter & Meaning & Value \\
\hline$\delta_{j p t}$ & Demand & {$[0 ; 80]$} \\
\hline$q_{r}$ & Maximum workload of a resource & {$[150 ; 190]$} \\
\hline$\xi_{r}$ & Workload related to distance & {$[0 \% ; 5 \%]$} \\
\hline$\tau_{p r}$ & Resource requirement for each pathology & {$[0.2 ; 2.5]$} \\
\hline$\eta_{p r}$ & Resource requirement for authorization & {$[0 ; 2]$} \\
\hline$\alpha$ & Validity length (time periods) of authorization & 2 \\
\hline$a_{r}^{+}$ & Resource employment cost & {$[3,000 € ; 6,000 €]$} \\
\hline$a_{r}^{-}$ & Resource dismissal cost & {$[3,000 € ; 4,500 €]$} \\
\hline$\gamma_{p}$ & Authorization cost & {$[100,000 € ; 125,000 €]$} \\
\hline$c_{p}$ & Penalty cost & $\infty$ \\
\hline$f_{i}$ & Opening cost for a HHC center & {$[10,000 € ; 15,000 €]$} \\
\hline$a_{r}$ & Resource salary & {$[50,000 € ; 100,000 €]$} \\
\hline
\end{tabular}

Table 1: Parameter variation for random generation of test data instances

\begin{tabular}{|c|c|c|c|c|c|}
\hline \multicolumn{3}{|c|}{ Scenarios } & \multicolumn{3}{|c|}{ Results } \\
\hline Id & Configuration & Gap/Time limit & Avg CPU (s) & Avg final gap & Stopped \\
\hline \multirow{3}{*}{ I } & \multirow{3}{*}{5.50 .5 .5 .1} & $0.5 \%$ & 0.665 & $0.108 \%$ & $0 \%$ \\
\hline & & $0.1 \%$ & 1.451 & $0.086 \%$ & $0 \%$ \\
\hline & & $0.05 \%$ & 65.373 & $0.047 \%$ & $0 \%$ \\
\hline \multirow{3}{*}{ II } & \multirow{3}{*}{5.50 .5 .10 .1} & $0.5 \%$ & 0.665 & $0.149 \%$ & $0 \%$ \\
\hline & & $0.1 \%$ & 5.538 & $0.088 \%$ & $0 \%$ \\
\hline & & $0.05 \%$ & 131.429 & $0.049 \%$ & $0 \%$ \\
\hline \multirow{3}{*}{ III } & \multirow{3}{*}{5.50 .10 .5 .1} & $0.5 \%$ & 1.324 & $0.045 \%$ & $0 \%$ \\
\hline & & $0.1 \%$ & 1.343 & $0.044 \%$ & $0 \%$ \\
\hline & & $0.05 \%$ & 2.306 & $0.036 \%$ & $0 \%$ \\
\hline \multirow{3}{*}{ IV } & \multirow{3}{*}{ 20.50.5.5.1 } & $0.5 \% / 900 \mathrm{~s}$ & 4.483 & $0.341 \%$ & $0 \%$ \\
\hline & & $0.1 \% / 900 \mathrm{~s}$ & 529.598 & $0.126 \%$ & $40 \%$ \\
\hline & & $0.05 \% / 900 \mathrm{~s}$ & 755.259 & $0.086 \%$ & $77 \%$ \\
\hline \multirow{3}{*}{ V } & \multirow{3}{*}{ 20.100.5.5.1 } & $0.5 \% / 900 \mathrm{~s}$ & 6.754 & $0.255 \%$ & $0 \%$ \\
\hline & & $0.1 \% / 900 \mathrm{~s}$ & 685.141 & $0.136 \%$ & $50 \%$ \\
\hline & & $0.05 \% / 900 \mathrm{~s}$ & 831.883 & $0.120 \%$ & $80 \%$ \\
\hline \multirow{3}{*}{ VI } & \multirow{3}{*}{5.50 .5 .5 .5} & $0.5 \% / 900 \mathrm{~s}$ & 4.512 & $0.287 \%$ & $0 \%$ \\
\hline & & $0.1 \% / 900 \mathrm{~s}$ & 291.802 & $0.090 \%$ & $20 \%$ \\
\hline & & $0.05 \% / 900 \mathrm{~s}$ & 891.725 & $0.077 \%$ & $83.3 \%$ \\
\hline \multirow{3}{*}{ VII } & \multirow{3}{*}{ 5.50.5.5.10 } & $0.5 \% / 900 \mathrm{~s}$ & 14.395 & $0.351 \%$ & $0 \%$ \\
\hline & & $0.1 \% / 900 \mathrm{~s}$ & 613.671 & $0.123 \%$ & $33.3 \%$ \\
\hline & & $0.05 \% / 900 \mathrm{~s}$ & 860.821 & $0.113 \%$ & $83.3 \%$ \\
\hline
\end{tabular}

Table 2: Results summary of the HHC location problem performance analysis 


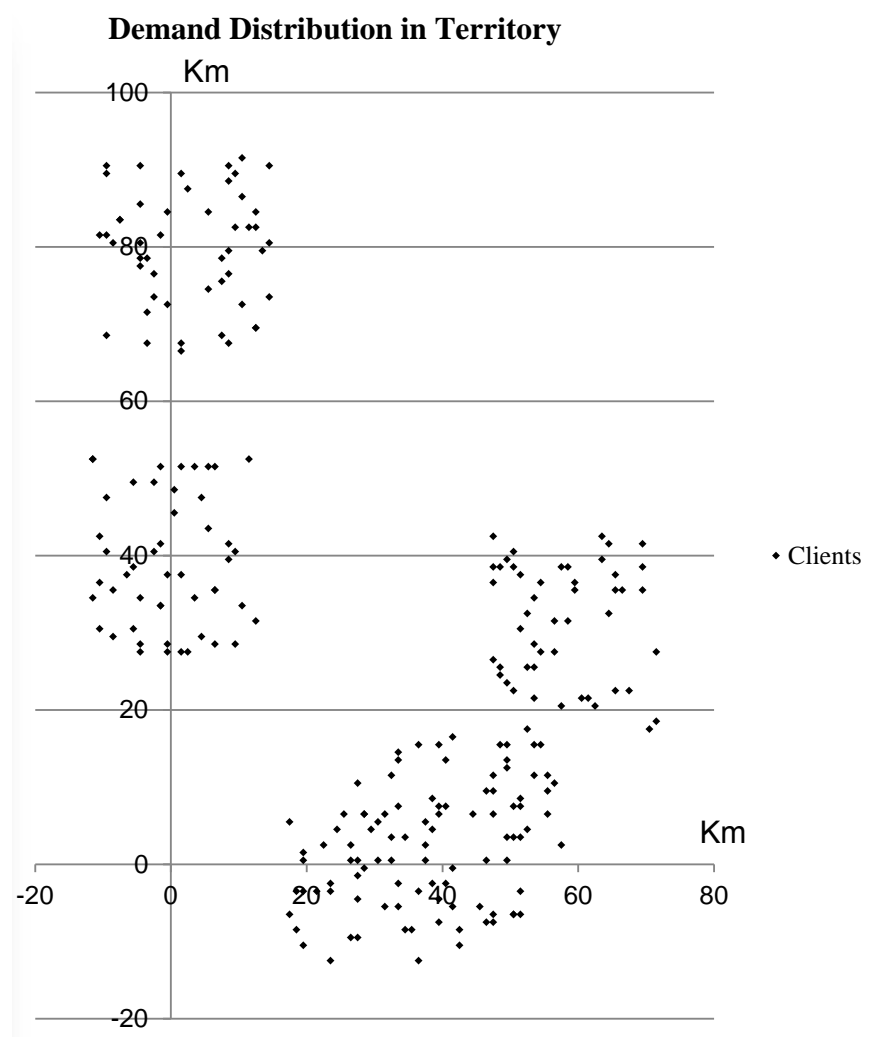

Figure 3: Demand zones generation example

time horizon length have also a high impact on quality of results. Other parameters (amount of pathologies, of resource types) have a low impact on optimization performance. Since we focus on a strategic optimization problem, long computational times are admissible. Further research on that point (construction of a meta heuristic for example) is out of the scope of the present paper.

\section{Tactical management of home health-care activities}

\subsection{Problem description}

In this section, we propose a direct extension of the HHC center location problem by taking into account the economic viability of the system. In this problem, we intend to ensure a tactical management of a HHC center, allowing to adapt itself to the evolving market. To answer the care demand, HHC centers should invest money in various processes. Five fundamental processes have been identified for HHC. Each process has a cost for the center which is different if the process is managed internally or if it is outsourced. Table 3 summarizes the processes and their features.

Assumption 8 (Outsourcing) For the sake of quality of care, it is not possible to partly outsource care activities for a certain demand zone. This point has been extensively discussed with health-care practitioners since it was indeed theoretically possible to partly outsource certain care activities.

Assumption 9 (Refund of activities) HHC activities benefit a certain refund from the state (social insurance). It means that certain activities may have a better refund than others depending on state policies. 


\begin{tabular}{|l|l|l|l|}
\hline Id & $\begin{array}{l}\text { Process } \\
\text { name }\end{array}$ & $\begin{array}{l}\text { External organization } \\
\text { (outsourcing) }\end{array}$ & $\begin{array}{l}\text { Internal organization } \\
\text { (own resources) }\end{array}$ \\
\hline P1 & $\begin{array}{l}\text { Activity coordi- } \\
\text { nation }\end{array}$ & Not permitted & $\begin{array}{l}\text { Coordination of care activities } \\
\text { by the center. }\end{array}$ \\
\hline P2 & $\begin{array}{l}\text { Medicines and } \\
\text { supplies distribu- } \\
\text { tion }\end{array}$ & $\begin{array}{l}\text { Use the town dispensaries } \\
\text { network or external service } \\
\text { providers. Each delivery has } \\
\text { a cost. }\end{array}$ & $\begin{array}{l}\text { Internal pharmacy and stor- } \\
\text { age rooms are necessary A } \\
\text { fleet of vehicule is also re- } \\
\text { quired for the distribution. }\end{array}$ \\
\hline P3 & $\begin{array}{l}\text { Consultation with } \\
\text { a specialist } \\
\text { Auired for the consultation. }\end{array}$ & $\begin{array}{l}\text { The center must have a spe- } \\
\text { cialist, inducing a fixed cost } \\
\text { for salary. }\end{array}$ \\
\hline P4 & $\begin{array}{l}\text { Care activities } \\
\text { The center hires freelance } \\
\text { nurses. }\end{array}$ & $\begin{array}{l}\text { center employs nurses } \\
\text { (fixed cost for salary). }\end{array}$ \\
\hline P5 & $\begin{array}{l}\text { Waste collection } \\
\text { and disposal }\end{array}$ & Same as P2. & Same as P2. \\
\hline
\end{tabular}

Table 3: HHC fundamental processes

Assumption 10 (Authorization) In this problem, $\eta_{\text {pri }}$ also depends on care process. It is the minimal amount of resources related to a process to ensure a certain level of care quality. Such amount is determined by health authorities and depends on the pathology.

\subsection{Formal model}

The problem consists in deciding for a HHC center which processes will be outsourced or not. We propose two models (A) and (B) with two different objectives: model (A) intends to minimize the costs for the HHC center, whereas model (B) intends to maximize demand coverage.

Indexes and sets:

- $P$ : set of pathologies, indexed by $p$.

- $R$ : set of resources, indexed by $r$.

- $J$ : set of demand zones, indexed by $j$.

- $I$ : set of activity processes, indexed by $i$.

Parameters:

- $\delta_{j p}$ : demand quantity for pathology $p$ in demand zone $j$.

- $d_{j}$ : distance between demand zone $j$ and the HHC center under consideration.

- $q_{r}$ : resource capacity (maximum load) of resource $r$.

- $\tau_{p r i}$ : workload of resource $r$ in process $i$ for pathology $p$.

- $\eta_{p r i}$ : minimal amount of resource $r$ in process $i$ required to get authorization for pathology $p$ in process $i$.

- $l_{j r}$ : amount of freelance resources $r$ available in demand zone $j$. 
- $\theta_{j}$ : transportation time inside demand zone $j$, used to approximate traveling time of resources inside a demand zone.

Costs parameters:

- $a_{r}$ : fixed cost for the salary of a resource $r$.

- $\gamma_{p}$ : fixed authorization cost for pathology $p$.

- $c_{i p}$ : variable cost per demand unit of process $i$ for pathology $p$ when outsourced.

- $b_{i p}$ : variable cost per demand unit of process $i$ for pathology $p$ when not outsourced. To calculate the costs of internal processes, we distinguish two types of sub costs: (i) $b_{i p} \in R_{0}$ process cost depending on distance, and (ii) $b_{i p} \in R_{1}$ for costs per demand unit.

- $f_{i p}$ : refund for process $i$ of pathology $p$.

- $W$ : total budget of the center.

Decision variables:

- $X_{j p i}=1$ if demand for service $i$ related to pathology $p$ in zone $j$ is managed using employed resources (not outsourced).

- $Z_{p}=1$ if the center pays the authorization to offer services related to pathology $p$.

- $N_{r}$ is the amount of resource units $r$ employed by the center.

- $Y_{j p i}=1$ if the service $i$ related to pathology $p$ in zone $j$ is outsourced.

The mathematical model A is formulated as follows:

$$
\begin{gathered}
\max \sum_{i, p} f_{i p} \sum_{j} \delta_{j p}\left(X_{j p i}+Y_{j p i}\right)-\sum_{i, p} c_{i p} \sum_{j} Y_{j p i}-\sum_{i, p \mid b_{i p} \in R_{1}} b_{i p} \sum_{j} X_{j p i} \delta_{j p} \\
-\sum_{i p \mid b_{i p} \in R_{0}} b_{i p} \sum_{j} X_{j p i}\left(d_{j}\left(1+\theta_{j}\right)\right)-\sum_{r} a_{r} N_{r}-\sum_{p} \gamma_{p} Z_{p}
\end{gathered}
$$

s.t.

$$
\begin{aligned}
\sum_{j, p, i} X_{j p i} \delta_{j p}\left(\tau_{r p i}+\left(d_{j}\left(1+\theta_{j}\right)\right) \leqslant q_{r} N_{r}\right. & \forall r \in R_{0} \\
X_{j p i}+Y_{j p i}=X_{j p 0} & \forall j, p, i \\
X_{j p i}+Y_{j p i}=1 & \forall j, p, i \\
X_{j p 0} \leqslant Z_{p} & \forall j, p \\
\eta_{p r} Z_{p} \leqslant N_{r} & \forall r, p \\
\sum_{p, i} Y_{j p i}\left(\delta_{j p} \tau_{r p i}\right) \leqslant l_{j r} q_{r} & \forall j, r \\
X_{j p i}, Y_{j p i}, Z_{p} \in\{0,1\} & \forall j, p, i \\
N_{r} \in \mathbb{N}^{*} & \forall r
\end{aligned}
$$

The objective function intends to maximize the benefit of the center and is the sum of: (i) total refund; (ii) outsourcing cost; (iii) internal resources cost; (iv) salaries costs; and (v) authorization cost. Constraints set (14) ensures capacity is not exceeded. Constraints set 15 
ensures all services of a demand are accepted and served. Constraints set (16) ensures the center can serve a demand using both outsourced and internal resources. Constraints set (17) forbids the coordination for a pathology if unauthorized. Constraints set (18) ensures a minimal amount of resources. Constraints set (19) limits outsourcing. Finally, constraints sets (20) and (21) defines the type of variables (binary and integer).

If the objective is the maximization of the coverage under a fixed budget $W$ (model $\mathrm{B}$ ), the following modifications are required. The objective function is stated as follows:

$$
\max \sum_{j p i} X_{j p i}
$$

Cost information in equation (13) should become a constraint:

$$
\begin{gathered}
\sum_{i p} c_{i p} \sum_{j} Y_{j p i}+\sum_{i p \mid b_{i p} \in R_{1}} b_{i p} \sum_{j} X_{j p i} \delta_{j p}+\sum_{i p \mid b_{i p} \in R_{0}} b_{i p} \sum_{j} X_{j p i}\left(d_{j}\left(1+\theta_{j}\right)\right) \\
+\sum_{r} a_{r} N_{r}+\sum_{p} \gamma_{p} Z_{p} \leqslant W
\end{gathered}
$$

Finally full coverage of demand is no longer required in model B. Constraints set (16) should be replaced the following set of constraints:

$$
X_{j p i}+Y_{j p i} \leqslant 1 \quad \forall j, p, i
$$

Numerical tests of the management optimization of HHC problem are presented along with the case study in the next Section. This model is intended to be run periodically by HHC centers managers to adjust the volume of outsourced activities. The process decomposition can be adjusted depending on the type of HHC center.

\section{Case study}

\subsection{Data collection}

Data collection consisted in gathering information if various databases such as demographic data, epidemiological data. The ATIH (Technical Agency for Hospital Information) information system was used to gather information related to the Loire department (Auvergne-Rhone-Alpes region, France), as presented in Figure 4 . The territory is divided into demand zones. For each urban center, a demand zone is defined. Patients are supposed to be uniformly distributed on the area around those points. The demand quantity in each zone is proportional to the population density, as illustrated previously in Figure 3. All demand zones are detailed in Table 4.

For the Loire department, there have been 72,074 HHC care days in 2011 for 1,687 stays. Among all pathologies, two have been selected for our case study: (i) palliative care $\left(p_{0}: 23,039\right.$ days $(32 \%)$ and 582 stays $(34 \%))$ and (ii) pain management $\left(p_{1}: 8,594\right.$ days (12\%) and 297 stays $(18 \%))$. The demand parameter $\delta_{j p}$ of the model is estimated using the following formula:

$$
\delta_{j p}=D_{p} \frac{\pi_{j}}{\sum_{j} \pi_{j}}
$$

where $\pi_{j}$ models the population of demand zone $j$ and $D_{p}$ models the total demand for pathology $p$ on the territory. 


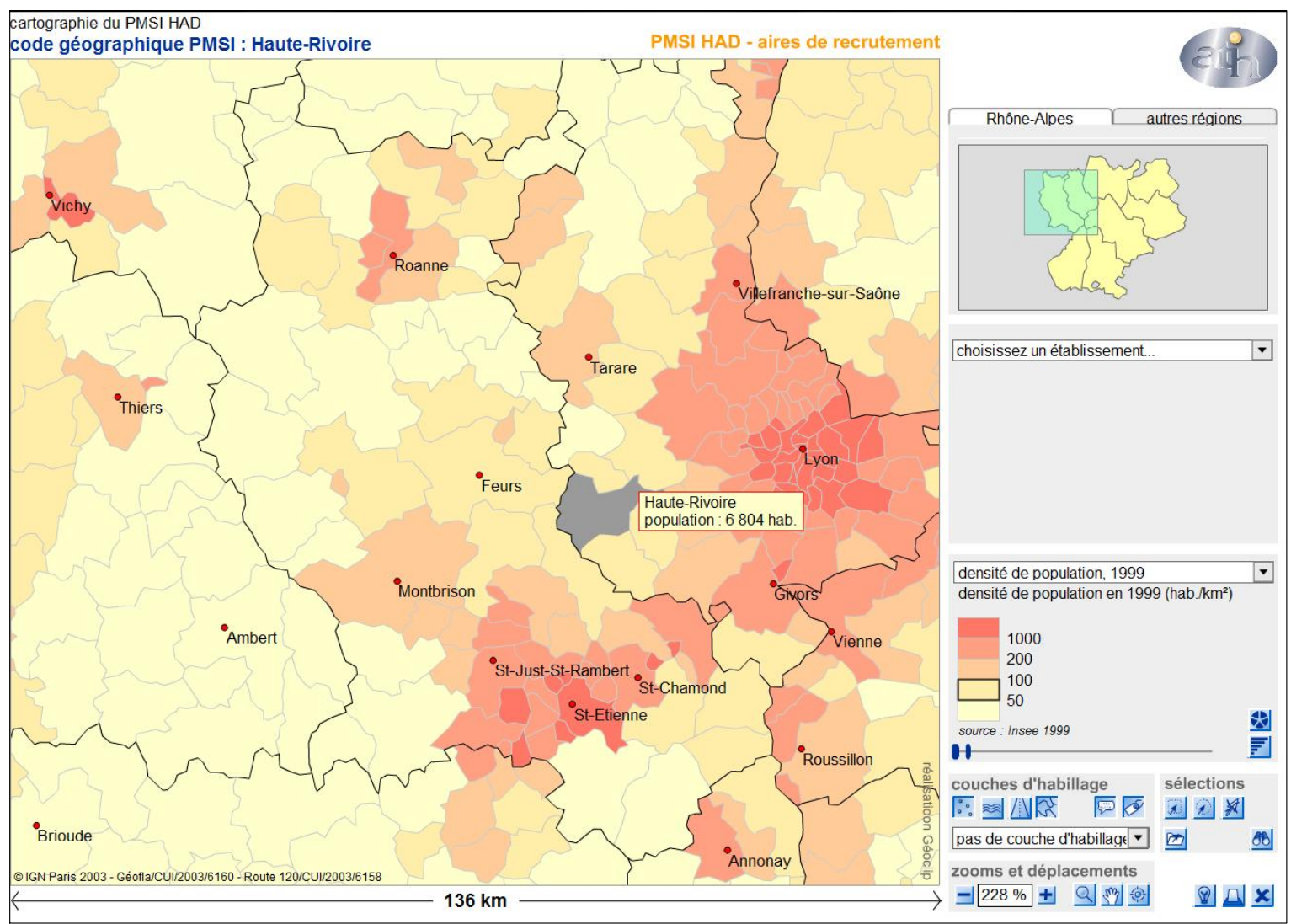

Figure 4: Geographical distribution of patients for the Loire department (from ATIH)

Resource requirements and related costs are also extracted from the ATIH information system, as presented in Table 5. For each resource type (nurse, carers, coordination staff, administrative staff and welcome staff) the salary has been estimated using national public function grids and indicators as presented in Table 6. For a pathology, utilization cost for each resource is known. For this point, we calculate the relative workload of each resource. By dividing the cost of a day of care by the daily cost, we obtain the daily workload of the resource per day of care (fourth column). Daily costs are also calculated. Finally, the workload is normalized among all resource types considered and the relative workload my be calculated. An estimation of the minimum amount of resources required to obtain the authorization has been calculated and presented in Table 20 in the appendices.

Finally, demand evolution can also be found in public databases. Figure 5 depicts demand evolution for both type of pathology in the Rhone-Alpes region from 2005 until 2011. It shows that (i) pain management care demand increases drastically since 2009 and (ii) the increase in palliative care slows down after 2010. In our case study, we use a time horizon of 7 periods and a demand evolution that fit the trend described in Figure 5 , i.e. a rapid increase for $p_{0}$ and a slow increase for $p_{1}$. 


\begin{tabular}{|c|c|c|c|c|c|}
\hline Zone & City & Pop. count & Zone & City & Pop. count \\
\hline 01 & Roanne & 50763 & 30 & St-Chamond & 37378 \\
\hline 02 & Régny & 3121 & 31 & Saint-Jean-Bonnefonds-2 & 3045 \\
\hline 03 & Montagny & 1394 & 32 & Saint-Paul-en-Jarez-2 & 3084 \\
\hline 04 & Coutouvre & 4797 & 33 & La Grand-Croix & 9448 \\
\hline 05 & Charlieu & 7256 & 34 & L'Horme & 4639 \\
\hline 06 & Pouilly-sous-Charlieu & 6677 & 35 & Lorette & 4843 \\
\hline 07 & Perreux & 14137 & 36 & Sorbiers-2 & 3699 \\
\hline 08 & Saint-Romain-la-Motte & 3631 & \multicolumn{2}{|r|}{ Total zones 30-36 } & 66136 \\
\hline 09 & Ambierle & 1728 & 37 & St-Etienne & 180210 \\
\hline 10 & Saint-Haon-le-Châtel & 7107 & 38 & St-Genest-Malifaux & 7865 \\
\hline 11 & Pouilly-les-Nonains & 6864 & 39 & Saint-Paul-en-Jarez-1 & 3084 \\
\hline 12 & Riorges & 10074 & 40 & Saint-Jean-Bonnefonds-1 & 3045 \\
\hline 13 & Cordelle & 1552 & 41 & Sorbiers-1 & 3699 \\
\hline \multicolumn{2}{|r|}{ Total zones $01-13$} & 119101 & 42 & La Talaudière & 6700 \\
\hline 14 & St-Just-St-Rambert & 13954 & 43 & L'Etrat & 3682 \\
\hline 15 & Saint-Marcellin-en-Forez-2 & 1687 & 44 & Saint-Priest-en-Jarez & 5812 \\
\hline 16 & Sury-le-Comtal-2 & 2402 & 45 & Villars & 8494 \\
\hline 17 & Andrézieux-Bouthéon & 15094 & 46 & Saint-Genest-Lerpt & 5672 \\
\hline 18 & Veauche & 9207 & 47 & Roche-La-Molire & 10083 \\
\hline 19 & Saint-Galmier & 11374 & 48 & Le Chambon-Feugerolles & 14090 \\
\hline 20 & Saint-Héand & 3722 & 49 & La Ricamarie & 8438 \\
\hline 21 & La-Fouillouse-1 & 2117 & 50 & La-Fouillouse-2 & 2117 \\
\hline \multicolumn{2}{|r|}{ Total zones $14-21$} & 59557 & \multicolumn{2}{|r|}{ Total zones $37-50$} & 262991 \\
\hline 22 & Feurs & 15349 & 51 & Montbrison & 26643 \\
\hline 23 & Rozier-en-Donzy & 1268 & 52 & Saint-Bonnet-le-Courreau & 1009 \\
\hline 24 & Panissières & 4270 & 53 & Saint-Georges-en-Couzan & 1846 \\
\hline 25 & Néronde & 6239 & 54 & Sail-sous-Couzan & 983 \\
\hline 26 & Chazelles-sur-Lyon & 9725 & 55 & Saint-Jean-Soleymieux & 3760 \\
\hline 27 & Montrond-les-Bains-1 & 5433 & 56 & Montrond-les-Bains-2 & 5433 \\
\hline 28 & Boen-1 & 4848 & 57 & Boen-2 & 4848 \\
\hline \multirow[t]{4}{*}{29} & Saint-Germain-Laval & 6017 & 58 & Saint-Marcellin-en-Forez-1 & 1687 \\
\hline & & & 59 & Sury-le-Comtal-1 & 2402 \\
\hline & Total zones 22-29 & 53150 & \multicolumn{2}{|r|}{ Total zones 51-59 } & 48612 \\
\hline & & & & Grand total & 609547 \\
\hline
\end{tabular}

Table 4: Population count in the main urban zones of the Loire department

\begin{tabular}{|l|l|l|c|l|l|}
\hline & Nurse & Carer & Coord. & Admin. staff & Welcome staff \\
\hline$p_{0}$ & $66.1 €(41.9 \%)$ & $29.5 €(18.7 \%)$ & $34.4 €(21.8 \%)$ & $17.7 €(11.2 \%)$ & $10.1 €(6.4 \%)$ \\
\hline$p_{1}$ & $54.8 €(41.1 \%)$ & $20.4 €(15.3 \%)$ & $35.3 €(26.5 \%)$ & $16.6 €(12.5 \%)$ & $6.2 €(4.7 \%)$ \\
\hline
\end{tabular}

Table 5: Cost of case study pathologies taken from national costs inquiry

\subsection{Home health-care centers location}

\subsubsection{Single period special case}

A design of experiments has been built in order to test the impact of the variation of two parameters: (i) the cost structure and (ii) the penalty cost (cost of giving traditional care in the hospital). Key performance indicators are:

1. Number of opened centers.

2. Number of treatments performed by the HHC centers or by the hospital.

3. Average/Maximum distance HHC centers-Patients.

4. Total cost per treatment performed by HHC centers.

5. Number of covered zones. 


\begin{tabular}{|l|c|c|c|c|c|}
\hline Resource & Daily & \multicolumn{2}{|c|}{ Daily workload } & \multicolumn{2}{c|}{ Rel. workload } \\
\cline { 3 - 6 } type & salary & $p_{0}$ & $p_{1}$ & $p_{0}$ & $p_{1}$ \\
\hline Nurse & $194.47 €$ & 0.339 & 0.282 & 0.40 & 0.4 \\
\hline Carer & $146.31 €$ & 0.202 & 0.139 & 0.24 & 0.20 \\
\hline Administrative staff & $243.55 €$ & 0.141 & 0.145 & 0.17 & 0.21 \\
\hline Coordination staff (med. secretary) & $162.98 €$ & 0.109 & 0.102 & 0.13 & 0.14 \\
\hline Welcoming staff (med. secretary) & $162.98 €$ & 0.062 & 0.038 & 0.07 & 0.05 \\
\hline
\end{tabular}

Table 6: Estimated relative workload for each resource type

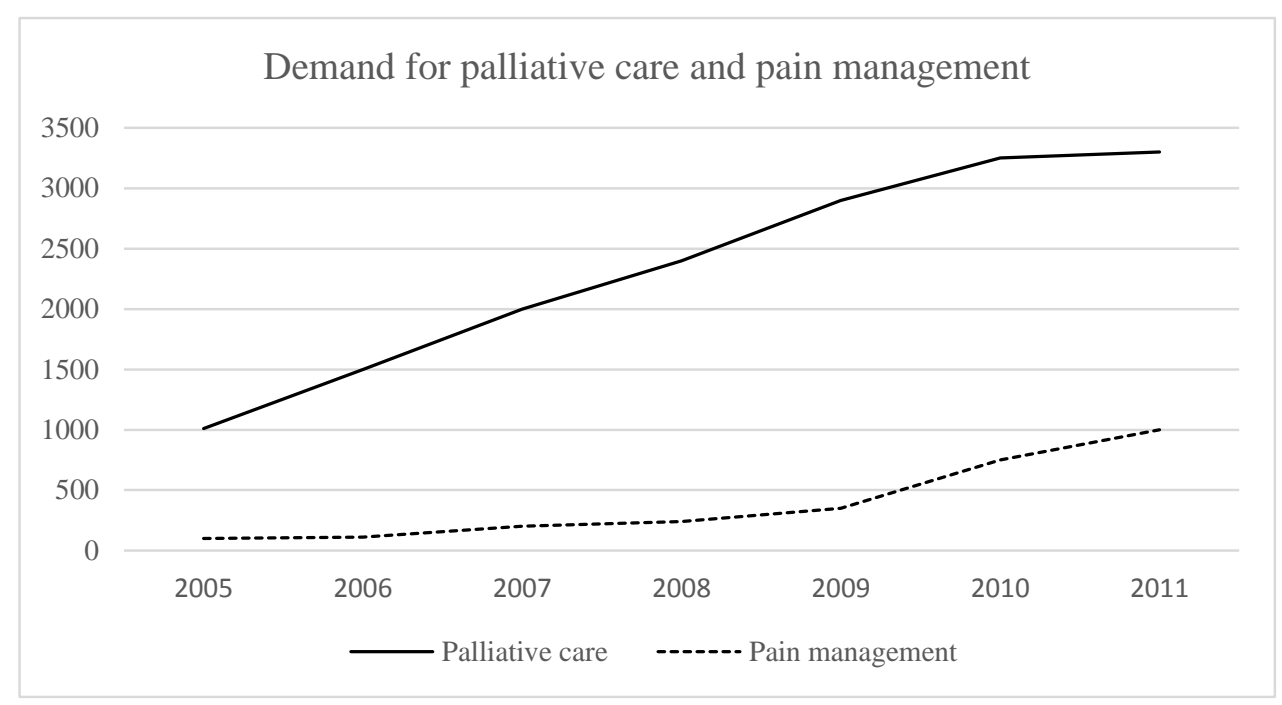

Figure 5: Demand for palliative care and pain management in the Rhone-Alps region between 2005 and 2011 (thousands of people) 
Three different situations are analyzed using economic parameters of the model: (i) treatments are performed in traditional health-care systems such as hospitals: opening costs are high compared to resource costs; (ii) small centers (facilities with smaller resource capacity/low employment rate) are opened; (iii) opening and authorization costs are low compared to resource costs. The design of experiment is presented in Table 7; a scenario (labeled I-IX in the first column) is defined by a cost structure which has been established with the help of health economists (columns 2-5: opening cost, salary, authorization cost, penalty cost).

Results are presented in Table 8. Population covering is not affected by the cost structure (other than penalty cost); the three first scenarios are set to understand the impact of fixed cost change for center opening. The number of opened centers decreases with cost increase as predicted. A $90 \%$ reduction of opening fixed cost brings a $22 \%$ increase of number of opened centers and a $2.06 \%$ decrease of average distance between patients and centers.

Scenarios I, IV and V were formulated to evaluate the impact of resources cost variation. It is the most important cost in our model since it creates a variation up to $94 \%$ of treatment cost. Such cost also impacts the number of opened centers: when resource cost decreases, big centers may employ more human resources, which makes small centers useless (however average distance between patients and centers increase, up to $39 \%$ between scenarios I and V).

Scenarios VI and VII show that authorization fixed cost has no impact on performance indicators, which goes against stereotypes. A comparison between scenario I (where 18 centers are opened) and VI/VII (where 23 centers are opened) shows that the opening of more centers reduces the average distance between patients and centers. By comparing scenarios II and VI, we notice that a diminution of authorization cost allows the opening of a new center, improving at the same time territorial coverage.

The total cost of HHC centers is important in our cost structure. Such parameter has a great impact on covering indicators. The proposed design of experiment allows to find a value for that parameter having the lowest impact on HHC coverage. Such estimator is important for decision makers, and can be used as a threshold to know whether HHC centers may be opened on a new territory or not.

\begin{tabular}{|c|l|r|r|r|r|}
\hline Id & Scenario & $\begin{array}{r}\text { Opening } \\
\text { cost }(€)\end{array}$ & $\begin{array}{r}\text { Salary } \\
(€)\end{array}$ & $\begin{array}{r}\text { Authorization } \\
\text { cost }(€)\end{array}$ & $\begin{array}{r}\text { Penalty } \\
\text { cost }(€)\end{array}$ \\
\hline I & Base scenario & 515,959 & 71,233 & 106,775 & $\infty$ \\
\hline II & Impact of opening cost $(\times 0.1)$ & 51,596 & 71,233 & 106,775 & $\infty$ \\
\hline III & Impact of opening cost $(\times 0.01)$ & 5,159 & 71,233 & 106,775 & $\infty$ \\
\hline IV & Impact of salary $(\times 0.1)$ & 51,596 & 7,123 & 106,775 & $\infty$ \\
\hline V & Impact of salary $(\times 0.01)$ & 51,596 & 712 & 106,775 & $\infty$ \\
\hline VI & Impact of auth. cost $(\times 0.1)$ & 51,596 & 71,233 & 10,677 & $\infty$ \\
\hline VII & Impact of auth. cost $(\times 0.01)$ & 51,596 & 71,233 & 1,067 & $\infty$ \\
\hline VIII & Impact of penalty cost & 51,596 & 71,233 & 106,775 & 100 \\
\hline IX & Impact of penalty cost & 51,596 & 71,233 & 106,775 & 50 \\
\hline
\end{tabular}

Table 7: Design of experiment for the single period case

\subsubsection{Multi period case}

The design of experiment presented in this section has been built to test the behavior of the model when several parameters vary over time: demand type, validity of authorizations, employment and dismissal costs. Scenarios settings are presented in Table 9. The first scenario is the base scenario. In that case, the demand for each time period and for each pathology is generated 


\begin{tabular}{|c|r|r|r|r|r|rc|}
\hline Id & $\begin{array}{r}\text { Number of } \\
\text { open struct. }\end{array}$ & $\begin{array}{r}\text { Number of } \\
\text { unassigned treat. }\end{array}$ & $\begin{array}{c}\text { Avg } \\
\text { dist. }\end{array}$ & $\begin{array}{c}\text { Max } \\
\text { dist. }\end{array}$ & $\begin{array}{r}\text { Avg cost per } \\
\text { treatment }\end{array}$ & \multicolumn{2}{|c|}{ Nb covered zones } \\
$p_{0}$ & $p_{1}$ \\
\hline I & 18 & 4154 & 2.91 & 5.67 & 69575 & 59 & 59 \\
\hline II & 22 & 4154 & 2.85 & 5.67 & 64538 & 59 & 59 \\
\hline III & 22 & 4154 & 2.85 & 5.67 & 64135 & 59 & 59 \\
\hline IV & 12 & 4154 & 3.47 & 6.07 & 9891 & 59 & 59 \\
\hline V & 8 & 4154 & 4.04 & 6.98 & 3790 & 59 & 59 \\
\hline VI & 23 & 4154 & 2.67 & 5.66 & 63413 & 59 & 59 \\
\hline VII & 23 & 4154 & 2.67 & 5.66 & 63324 & 59 & 59 \\
\hline VIII & 22 & 4154 & 2.85 & 5.66 & 64538 & 59 & 59 \\
\hline IX & 21 & 4030 & 2.66 & 4.57 & 59070 & 53 & 52 \\
\hline
\end{tabular}

Table 8: Results for the single period case

according to Figure 5. Another key performance indicator is considered for the multi period case to evaluate the stability of employment of HHC center. The stability factor of human resources is calculated using the following formula:

$$
\sum_{i r t}\left(Q_{i r t}^{+}+Q_{i r t}^{-}\right) /(|T| \times|I| \times|R|)
$$

This factor is used to identify solutions having frequent employment and dismissal of resources. If the factor is close to zero, the scenario is stable. Taking into account the results, the stability factor is highly dependent on employment and dismissal costs, and on unused capacity (see scenarios VII and VIII). All stability factors have a low value and are close to zero, showing that resource capacity do not change drastically from one period to another.

\begin{tabular}{|c|l|l|}
\hline Id & Scenario & Modified parameters \\
\hline I & Base scenario & None \\
\hline II & Demand increase & $+5 \%$ each period \\
\hline III & Demand decrease & $-5 \%$ each period \\
\hline IV & Authorization duration & $\alpha=4$ \\
\hline V & Dismissal cost & $a_{r}^{-} \times 10$ \\
\hline VI & Dismissal cost & $a_{r}^{-} \times 100$ \\
\hline VII & Employment cost & $a_{r}^{+} \times 10$ \\
\hline VIII & Employment cost & $a_{r}^{+} \times 100$ \\
\hline
\end{tabular}

Table 9: Design of experiment for the multi-period case

Results are presented in Table 10. Results of scenario II are close to the base scenario, only one additional center is opened. In scenario III, demand is decreasing in time: the unused capacity is higher than in the base scenario but the stability factor is lower. Since the demand is decreasing over the time horizon, too many resources are allocated. A longer authorization period in scenario IV allows HHC centers to treat more patients in the same period with a stable amount of resources.

Results of scenarios V and VI are proposed to observe the impact of dismissal cost variation. As expected, the unused capacity is lower when the cost is higher. Scenario VI has the lowest unused capacity. Distances between patients and centers are stable (average and maximum). The stability factor is higher in scenario VI than in scenario V but the total number of resources employed in scenarios V and VI are 4,220 and 4,647 respectively, meaning that even the high 
dismissal cost does not prevent a high number of employments. Finally, the variation of the employment cost of resources (scenarios VII and VIII) leads to an increase of the unused capacity because it is less costly than employing new resources. The number of opened centers decreases as well as the number of unassigned treatments (which is the lowest for all scenarios).

\begin{tabular}{|c|r|r|r|r|r|r|r|}
\hline Id & $\begin{array}{r}\text { Unused } \\
\text { capacity }\end{array}$ & $\begin{array}{r}\text { Number of } \\
\text { open struct. }\end{array}$ & $\begin{array}{r}\text { Number of } \\
\text { unassigned treat. }\end{array}$ & $\begin{array}{c}\text { Avg } \\
\text { dist. }\end{array}$ & $\begin{array}{c}\text { Max } \\
\text { dist. }\end{array}$ & $\begin{array}{r}\text { Avg cost per } \\
\text { treatment }\end{array}$ & $\begin{array}{r}\text { Stability } \\
\text { factor }\end{array}$ \\
\hline I & $1.061 \%$ & 14 & 255 & 4.43 & 8.56 & 64289 & 2.58 \\
\hline II & $1.025 \%$ & 15 & 245 & 4.35 & 8.68 & 64471 & 2.50 \\
\hline III & $1.618 \%$ & 14 & 124 & 4.06 & 7.55 & 68751 & 2.20 \\
\hline IV & $1.059 \%$ & 15 & 679 & 4.18 & 7.05 & 63818 & 2.68 \\
\hline V & $1.415 \%$ & 16 & 152 & 4.20 & 7.55 & 63582 & 2.71 \\
\hline VI & $1.022 \%$ & 15 & 175 & 4.11 & 7.55 & 63582 & 2.88 \\
\hline VII & $1.482 \%$ & 16 & 10 & 4.29 & 9.19 & 62838 & 2.90 \\
\hline VIII & $1.349 \%$ & 15 & & & & & 2.75 \\
\hline
\end{tabular}

Table 10: Results for the multi-period case

\subsection{Home health-care management}

For the HHC management problem case study, we focus on a HHC center located in AndrezieuxBoutheon city, in the center of the Loire territory. To calculate the variable cost for each process and for each pathology (parameter $b_{i p}$ ) we used the same database from the ATIH. The costs are presented in Table 11. The second column describes the daily cost outside of the center and the third column the average length of stay for each pathology in 2010. For each process, the cost are estimated such as the sum of all processes is equal to the treatment cost. Detailed values are presented in Table 23 in appendices. Parameters values are summarized in Table 12 .

\begin{tabular}{|c|r|r|r|}
\hline Pathology & Daily cost & Average LOS (days) & Cost of treatment \\
\hline Palliative care $\left(p_{0}\right)$ & $262.4 €$ & 22.2 & $5825.3 €$ \\
\hline Pain management $\left(p_{1}\right)$ & $358.5 €$ & 15.4 & $5520.9 €$ \\
\hline
\end{tabular}

Table 11: Input parameters for cost of treatments

\begin{tabular}{|c|c|c|}
\hline Parameter & Label & Value \\
\hline$\eta_{p r i}$ & Resources required for authorization & see Table 20 \\
\hline$q_{r}$ & Capacity & see Table 21 \\
\hline$a_{r}$ & Salary & see Table 21 \\
\hline$\tau_{p r i}$ & Resources requirement & see Table 22 \\
\hline$b_{i p}$ & Internal variable cost & see Table $\overline{23}$ \\
\hline$\delta_{j p}$ & Demand & {$[10,30]$} \\
\hline$l_{j r}$ & Available freelance resources & {$[0 ; 20]$} \\
\hline$\theta_{j}$ & Distance in a zone & {$[0.005 ; 0.025]$} \\
\hline$R_{1}$ & Variable costs depending on demand & {$\left[I_{0}, I_{2}, I_{3}\right]$} \\
\hline$R_{0}$ & Variable costs depending on distance & {$\left[I_{1}, I_{4}\right]$} \\
\hline
\end{tabular}

Table 12: Input parameters for the base scenario 


\subsubsection{Minimization of $\mathrm{HHC}$ costs under demand satisfaction constraint}

This design of experiment is related to model (A). Base scenario input parameters and performance indicators are listed in Table 12 . Three sets of experiments are proposed through the variation of three parameters:

1. Cost of outsourced processes $\left(c_{i p}\right)$ : this experiment intends to help understand the impact of the cost of outsourced processes versus internal processes (ratio $c_{i p} / b_{i p}$ ). This experiment is interesting to determine the best policy health authorities should encourage through state refunds.

2. Availability of external resources $\left(l_{j r}\right)$ : this experiment allows to understand the impact of territory characteristic such as freelance resource availability of the economic stability of the center.

3. Salary $\left(a_{r}\right)$ : this experiment allows to adjust the salary of resources depending on the environment. This design of experiment is useful for HHC managers who wants to adjust their expenses to remain competitive on their local territory.

Results of this experiment are presented in Table 13 with performance indicators related to the amount of outsourced processes for the considered demand, and in Table 14 with the usage of freelance resources.

Regarding the variation the cost of outsourced processes $\left(c_{i p}\right)$, demand assignment distribution is stable at around $50 \%$ for internal and outsourced, as shown in Table 13 . Relevant changes in results are obtained with a 10,000 factor between outsourced and internal costs. It means that hiring freelance resources for $\mathrm{HHC}$ is always a good solution and allows a more flexible management of the HHC center, even if its cost is higher. Lowest treatment costs (Table 14) are achieved when outsourced and internal process have similar values.

The second group of experiments (availability of external resources $l_{j r}$ is useful to adjust HHC center activity. The ratio internal/outsourced is sensible to that change for a certain interval. Medicine distribution activity is the most stable unless in the last scenario. Table 14 shows a decrease in the number of freelance resources used, as well as a decrease in the ratio of external costs.

Finally, model sensitivity has been tested with a variation of resources salaries $\left(a_{r}\right)$. As expected, more resources are employed when the cost is lower, inducing a higher ratio of internally managed processes. On an other hand, freelance resources usage is highly reduced. In the light of these results, a manager of HHC center should adjust the salary depending on the availability of freelance resources in the territory where it is implanted.

\subsubsection{Maximization of coverage under fixed budget}

This set of tests is related to model (B). Experiments are based on budget variation to evaluate the sensitivity of the solution considering a change in the budget. As base scenario, we propose a relaxation of budget constraint $(W=\infty)$. Results are presented in Table 15 and Table 16 .

Covering reduction accordingly to budget decrease is the first major impact. If we compare the last scenario ( $W=25 \mathrm{M} €$ ) with the base scenario, maximum covering is reached but the last scenario has better results considering unused capacity and treatment cost. Such analysis show the limitations of our method which is based on mono-objective optimization. Multi-objective optimization is a good alternative to solve this problem and will be considered for future works.

Using this approach, a HHC center manager is able to determine the best budget $W$ to maximize employed resources occupation and control the demand assignment. Freelance resources are used as an adjustment factor which allows flexibility in HHC center management. In this 


\begin{tabular}{|c|c|c|c|c|c|c|c|c|c|}
\hline & \multirow[t]{2}{*}{ Value } & \multirow{2}{*}{$\begin{array}{l}\text { Unused } \\
\text { capacity }\end{array}$} & \multicolumn{2}{|c|}{ Management } & \multicolumn{5}{|c|}{ \% internal management } \\
\hline & & & Internal & Outsourcing & $I_{0}$ & $I_{1}$ & $I_{2}$ & $I_{3}$ & $I_{4}$ \\
\hline \multirow[t]{4}{*}{$c_{i p}$} & $b_{i p}$ & $6.3 \%$ & $46.7 \%$ & $53.3 \%$ & $100 \%$ & $15 \%$ & $57.5 \%$ & $15 \%$ & $45.8 \%$ \\
\hline & $b_{i p} \times 100$ & $7.05 \%$ & $46.8 \%$ & $53.2 \%$ & $100 \%$ & $17.5 \%$ & $54.2 \%$ & $25.8 \%$ & $36.7 \%$ \\
\hline & $b_{i p} \times 1,000$ & $4.66 \%$ & $50.3 \%$ & $49.7 \%$ & $100 \%$ & $19.2 \%$ & $54.2 \%$ & $42.5 \%$ & $35.8 \%$ \\
\hline & $b_{i p} \times 10,000$ & $4.36 \%$ & $68.2 \%$ & $31.8 \%$ & $100 \%$ & $50.8 \%$ & $58.3 \%$ & $96.7 \%$ & $35.0 \%$ \\
\hline \multirow[t]{4}{*}{$l_{r j}$} & {$[0,10]$} & $9.14 \%$ & $33.5 \%$ & $66.5 \%$ & $100 \%$ & $11.7 \%$ & $20.0 \%$ & $14.2 \%$ & $21.7 \%$ \\
\hline & {$[0,2]$} & $11.03 \%$ & $36.8 \%$ & $63.2 \%$ & $100 \%$ & $11.7 \%$ & $31.7 \%$ & $15.0 \%$ & $25.8 \%$ \\
\hline & {$[0,1]$} & $8.42 \%$ & $42.5 \%$ & $57.5 \%$ & $100 \%$ & $11.7 \%$ & $42.5 \%$ & $20.8 \%$ & $37.5 \%$ \\
\hline & {$[0,0.667]$} & $4.66 \%$ & $50.3 \%$ & $49.7 \%$ & $100 \%$ & $19.2 \%$ & $54.2 \%$ & $42.5 \%$ & $35.8 \%$ \\
\hline \multirow[t]{6}{*}{$a_{r}$} & $a_{r} \times 0.01$ & $3.30 \%$ & $94.5 \%$ & $5.5 \%$ & $100 \%$ & $100 \%$ & $100 \%$ & $100 \%$ & $70.0 \%$ \\
\hline & $a_{r} \times 0.03$ & $3.76 \%$ & $79.4 \%$ & $20.6 \%$ & $100 \%$ & $93.3 \%$ & $72.5 \%$ & $100 \%$ & $30.8 \%$ \\
\hline & $a_{r} \times 0.05$ & $3.15 \%$ & $70.3 \%$ & $29.7 \%$ & $100 \%$ & $75.8 \%$ & $45.8 \%$ & $100 \%$ & $29.2 \%$ \\
\hline & $a_{r} \times 0.08$ & $3.35 \%$ & $63.8 \%$ & $36.2 \%$ & $100 \%$ & $60.0 \%$ & $32.5 \%$ & $100 \%$ & $25.8 \%$ \\
\hline & $a_{r} \times 0.1$ & $2.92 \%$ & $60.0 \%$ & $40.0 \%$ & $100 \%$ & $47.5 \%$ & $30 \%$ & $95.8 \%$ & $24.2 \%$ \\
\hline & $a_{r}$ & $9.14 \%$ & $34.5 \%$ & $65.5 \%$ & $100 \%$ & $11.7 \%$ & $20 \%$ & $14.2 \%$ & $21.7 \%$ \\
\hline
\end{tabular}

Table 13: Parameter variation impact on management

\begin{tabular}{|c|c|c|c|c|c|c|c|c|c|c|}
\hline & \multirow[t]{2}{*}{ Value } & \multirow{2}{*}{$\begin{array}{l}\text { Ratio of } \\
\text { freelance }\end{array}$} & \multicolumn{5}{|c|}{ Freelance resources usage } & \multicolumn{2}{|c|}{ Budget allocation } & \multirow{2}{*}{$\begin{array}{r}\text { Treatment } \\
\text { cost }(€)\end{array}$} \\
\hline & & & $R_{0}$ & $R_{1}$ & $R_{2}$ & $R_{3}$ & $R_{4}$ & Outsourced & Internal & \\
\hline \multirow[t]{4}{*}{$c_{i p}$} & $b_{i p}$ & $26.5 \%$ & 8.75 & 4.68 & 4.63 & 2.95 & 3.95 & $0.01 \%$ & $99.99 \%$ & 338023 \\
\hline & $b_{i p} \times 100$ & $28.1 \%$ & 9.88 & 4.47 & 4.81 & 3.27 & 3.97 & $1.28 \%$ & $98.72 \%$ & 343473 \\
\hline & $b_{i p} \times 1,000$ & $27.2 \%$ & 9.90 & 3.96 & 4.60 & 3.31 & 3.84 & $9.40 \%$ & $90.60 \%$ & 379628 \\
\hline & $b_{i p} \times 10,000$ & $21.5 \%$ & 9.30 & 1.68 & 3.43 & 3.11 & 2.76 & $16.54 \%$ & $83.46 \%$ & 531296 \\
\hline \multirow[t]{4}{*}{$l_{j r}$} & {$[0,10]$} & $2.8 \%$ & 17.54 & 6.36 & 6.53 & 4.41 & 4.68 & $17.01 \%$ & $82.99 \%$ & 302230 \\
\hline & {$[0,2]$} & $12.6 \%$ & 14.85 & 5.83 & 6.07 & 4.12 & 4.60 & $15.61 \%$ & $84.39 \%$ & 322495 \\
\hline & {$[0,1]$} & $22.2 \%$ & 12.79 & 5.32 & 5.34 & 3.55 & 4.24 & $13.08 \%$ & $86.92 \%$ & 356635 \\
\hline & {$[0,0.667]$} & $27.2 \%$ & 9.90 & 3.96 & 4.60 & 3.31 & 3.84 & $9.39 \%$ & $90.61 \%$ & 379983 \\
\hline \multirow[t]{6}{*}{$a_{r}$} & $a_{r} \times 0.01$ & $0.1 \%$ & 0.97 & 0.00 & 1.13 & 1.24 & 0.88 & $0.27 \%$ & $99.73 \%$ & 152535 \\
\hline & $a_{r} \times 0.03$ & $0.6 \%$ & 8.14 & 1.21 & 3.17 & 3.00 & 1.96 & $1.77 \%$ & $98.23 \%$ & 163883 \\
\hline & $a_{r} \times 0.05$ & $0.9 \%$ & 13.29 & 2.22 & 3.94 & 3.50 & 2.41 & $3.37 \%$ & $96.63 \%$ & 173393 \\
\hline & $a_{r} \times 0.08$ & $1.0 \%$ & 15.72 & 2.69 & 4.44 & 3.85 & 2.86 & $4.34 \%$ & $95.66 \%$ & 185937 \\
\hline & $a_{r} \times 0.1$ & $1.1 \%$ & 16.03 & 3.02 & 4.68 & 3.98 & 3.17 & $5.61 \%$ & $94.39 \%$ & 193682 \\
\hline & $a_{r}$ & $1.4 \%$ & 17.54 & 6.36 & 6.53 & 4.41 & 4.68 & $11.52 \%$ & $88.48 \%$ & 446245 \\
\hline
\end{tabular}

Table 14: Parameter variation impact on freelance resources usage 
example, a $10 \mathrm{M} €$ budget is enough to assign more than $80 \%$ of the demand for a treatment cost of $200 \mathrm{~K} €$. Increasing the budget is not worthy considering the associated expenses (more than $300 \mathrm{~K} €)$.

\begin{tabular}{|r|r|r|r|r|r|r|r|r|r|}
\hline$W$ & Unused & \multicolumn{2}{|c|}{ Demand assignment (coverage) } & \multicolumn{4}{|c|}{ \% internal management } \\
\cline { 3 - 9 } & capacity & Internal & Outsourced & Total & $I_{0}$ & $I_{1}$ & $I_{2}$ & $I_{3}$ & $I_{4}$ \\
\hline$\infty$ & $30.65 \%$ & $68 \%$ & $32 \%$ & $100 \%$ & $100 \%$ & $59.2 \%$ & $57.5 \%$ & $60.0 \%$ & $64.2 \%$ \\
$1,000,000$ & $4.60 \%$ & $8 \%$ & $10 \%$ & $18 \%$ & $18.3 \%$ & $0.8 \%$ & $3.3 \%$ & $14.2 \%$ & $3.3 \%$ \\
$2,500,000$ & $3.68 \%$ & $11 \%$ & $19 \%$ & $30 \%$ & $30.0 \%$ & $1.7 \%$ & $3.3 \%$ & $14.2 \%$ & $4.2 \%$ \\
$5,000,000$ & $1.39 \%$ & $18 \%$ & $39 \%$ & $57 \%$ & $56.7 \%$ & $2.5 \%$ & $6.7 \%$ & $17.5 \%$ & $5.8 \%$ \\
$7,500,000$ & $1.86 \%$ & $22 \%$ & $48 \%$ & $69 \%$ & $69.2 \%$ & $4.2 \%$ & $7.5 \%$ & $19.2 \%$ & $8.3 \%$ \\
$10,000,000$ & $0.95 \%$ & $28 \%$ & $57 \%$ & $84 \%$ & $84.2 \%$ & $9.2 \%$ & $10.0 \%$ & $21.7 \%$ & $13.3 \%$ \\
$25,000,000$ & $0.09 \%$ & $34 \%$ & $67 \%$ & $100 \%$ & $100 \%$ & $11.7 \%$ & $20.0 \%$ & $14.2 \%$ & $21.7 \%$ \\
\hline
\end{tabular}

Table 15: Budget variation impact on management

\begin{tabular}{|c|c|c|c|c|c|c|c|c|}
\hline \multirow[t]{2}{*}{ W } & \multicolumn{5}{|c|}{ Freelance resources usage } & \multicolumn{2}{|c|}{ Budget allocation } & \multirow{2}{*}{$\begin{array}{r}\text { Treatment } \\
\text { cost }(€)\end{array}$} \\
\hline & $R_{0}$ & $R_{1}$ & $R_{2}$ & $R_{3}$ & $R_{4}$ & Outsourced & Internal & \\
\hline$\infty$ & 8.9 & 3.1 & 3.0 & 2.0 & 2.1 & $3.34 \%$ & $96.66 \%$ & 740589 \\
\hline $1,000,000$ & 2.8 & 0.7 & 0.9 & 0.7 & 0.7 & $24.98 \%$ & $75.03 \%$ & 88743 \\
\hline $2,500,000$ & 5.4 & 1.6 & 1.8 & 1.3 & 1.3 & $31.33 \%$ & $68.67 \%$ & 110184 \\
\hline $5,000,000$ & 10.4 & 3.3 & 3.7 & 2.7 & 2.7 & $30.52 \%$ & $69.49 \%$ & 146099 \\
\hline $7,500,000$ & 13.2 & 4.3 & 4.7 & 3.3 & 3.4 & $27.46 \%$ & $72.54 \%$ & 168157 \\
\hline $10,000,000$ & 15.7 & 5.2 & 5.6 & 3.9 & 3.9 & $23.61 \%$ & $76.39 \%$ & 197756 \\
\hline $25,000,000$ & 17.5 & 6.4 & 6.5 & 4.4 & 4.7 & $17.01 \%$ & $82.99 \%$ & 302230 \\
\hline
\end{tabular}

Table 16: Budget variation impact on freelance resources usage

\section{Conclusions and perspectives}

In this paper we proposed a comprehensive methodology for the design and the management of a home health-care network taking into account medical demand evolution in a territory and a complex cost structure adapted to our problem. The first optimization model provides a strategic location plan for home health-care centers across a territory, demand assignment and resource sizing. The model is solved for a single and multi-period time horizon. The second optimization model provides a tactical management plan for the crucial activities of each HHC center by deciding if certain activities should be outsourced or not. Both models have been tested on a realistic case study using real data from the Loire department (France). Various scenarios have been tested to study the behavior of the models. Results are also realistic and relevant for stakeholders (health authorities and HHC centers managers), inducing that the methodology can be applied for real size case studies. Stability factors have also been introduced to take into account social constraints related to working conditions of health-care practitioners.

Choosing the location of HHC centers across a territory has a high impact on resource sizing, demand assignment and pathologies to be treated. Thus the economic viability of a HHC center is strongly correlated to its localization in the network with regards to other health-care hubs such as hospitals. Taking into account the economic fragility of HHC centers in developed countries, decision aid tools and methodologies are crucial to optimize the operations of a home health-care network. Collaboration between HHC centers is also important to optimize the global performance of the network: the global assignment of the demand in a territory is more efficient than the local optimization of a center.

This paper provides a comprehensive toolbox for both HHC centers managers and regional health agencies to better organize the deployment of home health care across a territory taking 
into account its characteristics (freelance health resources availability, demand dynamic, traveling distances). The strategic plan allows an efficient coverage of a territory to satisfy the demand under while minimizing costs. To ensure the economic stability of HHC, design of experiments are provided, allowing a fine tuning of centers management through adjustment of salaries and the determination of a ratio of outsourced activities.

For future works, we need to extend the case studies of the proposed models to include different territory configurations, including special characteristics such as map topology (inducing long traveling distances for certain zones). In order to better fit the varying demand over the time horizon, it is also possible to improve both strategic and tactical optimization models by including random variables. Stochastic optimization using scenarios may lead to more accurate solutions. Finally, we intend to provide a performance evaluation of the proposed organization using discrete-event simulation in order to capture the complex processes related to the visit of practitioners at home.

\section{Appendices}

Auxiliary data used as input for the models are presented in this section. Estimation of the demand in zones is presented in Table 17. Distance matrix between main zones is presented in Table 18. Resource requirements for palliative care and pain management are presented in Table 19. we suppose that the duration for a visit to a patient for palliative care (resp. pain management) is 5 hours (resp. 3 hours). Minimal amount of resources required to get the authorization for certain type of care is presented in Table 20. Resource capacity, distance assignment ratio and fixed costs are presented in Table 21. For the management optimization problem, resource requirements $\left(\tau_{r p i}\right)$ have been recalculated to get significant behavior. These parameters are presented in Table 22 . Table 23 presents costs of all processes for each pathology.

\begin{tabular}{|l|l|l|l|l|l|l|l|l|l|l|l|}
\hline$j$ & $\delta_{j 0}$ & $\delta_{j 1}$ & $j$ & $\delta_{j 0}$ & $\delta_{j 1}$ & $j$ & $\delta_{j 0}$ & $\delta_{j 1}$ & $j$ & $\delta_{j 0}$ & $\delta_{j 1}$ \\
\hline $\mathbf{1}$ & 48 & 25 & $\mathbf{1 6}$ & 2 & 1 & $\mathbf{3 1}$ & 3 & 1 & $\mathbf{4 6}$ & 5 & 3 \\
$\mathbf{2}$ & 3 & 2 & $\mathbf{1 7}$ & 14 & 7 & $\mathbf{3 2}$ & 3 & 2 & $\mathbf{4 7}$ & 10 & 5 \\
$\mathbf{3}$ & 1 & 1 & $\mathbf{1 8}$ & 9 & 4 & $\mathbf{3 3}$ & 9 & 5 & $\mathbf{4 8}$ & 13 & 7 \\
$\mathbf{4}$ & 5 & 2 & $\mathbf{1 9}$ & 11 & 6 & $\mathbf{3 4}$ & 4 & 2 & $\mathbf{4 9}$ & 8 & 4 \\
$\mathbf{5}$ & 7 & 4 & $\mathbf{2 0}$ & 4 & 2 & $\mathbf{3 5}$ & 5 & 2 & $\mathbf{5 0}$ & 2 & 1 \\
$\mathbf{6}$ & 6 & 3 & $\mathbf{2 1}$ & 2 & 1 & $\mathbf{3 6}$ & 4 & 2 & $\mathbf{5 1}$ & 25 & 13 \\
$\mathbf{7}$ & 13 & 7 & $\mathbf{2 2}$ & 15 & 7 & $\mathbf{3 7}$ & 172 & 88 & $\mathbf{5 2}$ & 1 & 0 \\
$\mathbf{8}$ & 3 & 2 & $\mathbf{2 3}$ & 1 & 1 & $\mathbf{3 8}$ & 8 & 4 & $\mathbf{5 3}$ & 2 & 1 \\
$\mathbf{9}$ & 2 & 1 & $\mathbf{2 4}$ & 4 & 2 & $\mathbf{3 9}$ & 3 & 2 & $\mathbf{5 4}$ & 1 & 0 \\
$\mathbf{1 0}$ & 7 & 3 & $\mathbf{2 5}$ & 6 & 3 & $\mathbf{4 0}$ & 3 & 1 & $\mathbf{5 5}$ & 4 & 2 \\
$\mathbf{1 1}$ & 7 & 3 & $\mathbf{2 6}$ & 9 & 5 & $\mathbf{4 1}$ & 4 & 2 & $\mathbf{5 6}$ & 5 & 3 \\
$\mathbf{1 2}$ & 10 & 5 & $\mathbf{2 7}$ & 5 & 3 & $\mathbf{4 2}$ & 6 & 3 & $\mathbf{5 7}$ & 5 & 2 \\
$\mathbf{1 3}$ & 1 & 1 & $\mathbf{2 8}$ & 5 & 2 & $\mathbf{4 3}$ & 4 & 2 & $\mathbf{5 8}$ & 2 & 1 \\
$\mathbf{1 4}$ & 13 & 7 & $\mathbf{2 9}$ & 6 & 3 & $\mathbf{4 4}$ & 6 & 3 & $\mathbf{5 9}$ & 2 & 1 \\
$\mathbf{1 5}$ & 2 & 1 & $\mathbf{3 0}$ & 36 & 18 & $\mathbf{4 5}$ & 8 & 4 & \multicolumn{1}{|c}{} \\
\cline { 1 - 5 } & & \multicolumn{7}{|c|}{} &
\end{tabular}

Table 17: Demand distribution according to population count $\left(\delta_{j p}\right)$

\section{Acknowledgments}

The authors are grateful to anonymous reviewers for their useful comments about the article. 


\begin{tabular}{|c|c|c|c|c|c|c|}
\hline & $\mathbf{1}$ & $\mathbf{1 4}$ & $\mathbf{2 2}$ & $\mathbf{3 0}$ & $\mathbf{3 7}$ & $\mathbf{5 1}$ \\
\hline $\mathbf{1}$ & 0 & 59 & 40 & 67 & 63 & 56 \\
$\mathbf{1 4}$ & & 0 & 32 & 27 & 23 & 31 \\
$\mathbf{2 2}$ & & & 0 & 41 & 38 & 30 \\
$\mathbf{3 0}$ & & & & 0 & 21 & 43 \\
$\mathbf{3 7}$ & & & & & 0 & 42 \\
$\mathbf{5 1}$ & & & & & & 0 \\
\hline
\end{tabular}

Table 18: Distance matrix

\begin{tabular}{|c|c|c|c|c|c|}
\hline$P$ & $\tau_{p 0}$ & $\tau_{p 1}$ & $\tau_{p 2}$ & $\tau_{p 3}$ & $\tau_{p 4}$ \\
\hline$P_{0}$ & $2 \mathrm{~h}$ & $1.2 \mathrm{~h}$ & $0.8 \mathrm{~h}$ & $0.6 \mathrm{~h}$ & $0.4 \mathrm{~h}$ \\
\hline$P_{1}$ & $1.2 \mathrm{~h}$ & $0.6 \mathrm{~h}$ & $0.6 \mathrm{~h}$ & $0.4 \mathrm{~h}$ & $0.2 \mathrm{~h}$ \\
\hline
\end{tabular}

Table 19: Resource required depending on pathologies $\tau_{p r}$

\begin{tabular}{|c|c|c|c|c|c|}
\hline$P$ & $\eta_{p 0}$ & $\eta_{p 1}$ & $\eta_{p 2}$ & $\eta_{p 3}$ & $\eta_{p 4}$ \\
\hline$P_{0}$ & 1 & 1 & 0 & 0 & 0 \\
\hline$P_{1}$ & 1 & 0 & 0 & 1 & 0 \\
\hline
\end{tabular}

Table 20: Minimal resource amount required for authorization $\left(\eta_{p r}\right)$

\begin{tabular}{|c|c|c|c|c|c|}
\hline & $r_{0}$ & $r_{1}$ & $r_{2}$ & $r_{3}$ & $r_{4}$ \\
\hline$q_{r}$ & $175 \mathrm{~h}$ & $190 \mathrm{~h}$ & $150 \mathrm{~h}$ & $175 \mathrm{~h}$ & $150 \mathrm{~h}$ \\
\hline$\xi_{r}$ & 0.05 & 0.05 & 0 & 0 & 0 \\
\hline$a_{r}$ & 70010 & 52674 & 87689 & 58675 & 58675 \\
\hline
\end{tabular}

Table 21: Resource capacity $\left(q_{r}\right)$, distance assignment ratio $\left(\xi_{r}\right)$ and fixed costs $\left(a_{r}\right)$

\begin{tabular}{|c|c|c|c|c|c|c|c|c|c|c|}
\hline & \multicolumn{7}{|c|}{$P_{0}$} & \multicolumn{5}{c|}{$P_{1}$} \\
\hline & $R_{0}$ & $R_{1}$ & $R_{2}$ & $R_{3}$ & $R_{4}$ & $R_{0}$ & $R_{1}$ & $R_{2}$ & $R_{3}$ & $R_{4}$ \\
\hline$i_{0}$ & 0 & 0.4 & 0.2 & 0.1 & 0 & 0 & 0.2 & 0.2 & 0.1 & 0.1 \\
\hline$i_{1}$ & 0 & 0 & 0.1 & 0.1 & 0.2 & 0 & 0 & 0 & 0 & 0.1 \\
\hline$i_{2}$ & 1.8 & 0.4 & 0.2 & 0.1 & 0 & 1 & 0.2 & 0.1 & 0.1 & 0 \\
\hline$i_{3}$ & 0 & 0.4 & 0.1 & 0 & 0 & 0 & 0.2 & 0.1 & 0 & 0.1 \\
\hline$i_{4}$ & 0.2 & 0 & 0.2 & 0.3 & 0.2 & 0.2 & 0 & 0.2 & 0.2 & 0.1 \\
\hline$\sum_{i} \tau_{r p i}$ & $2 \mathrm{~h}$ & $1.2 \mathrm{~h}$ & $0.8 \mathrm{~h}$ & $0.6 \mathrm{~h}$ & $0.4 \mathrm{~h}$ & $1.2 \mathrm{~h}$ & $0.6 \mathrm{~h}$ & $0.6 \mathrm{~h}$ & $0.4 \mathrm{~h}$ & $0.2 \mathrm{~h}$ \\
\hline
\end{tabular}

Table 22: Resource requirements $\left(\tau_{p r i}\right)$ 


\begin{tabular}{|c|c|l|r|r|}
\hline & Process & Label & $P_{0}$ & $P_{1}$ \\
\hline$I_{0}$ & Coordination & $\begin{array}{l}\text { Diagnosis, medical and social } \\
\text { care coordination }\end{array}$ & 36.9 & 32.1 \\
\hline$I_{1}$ & Distribution & $\begin{array}{l}\text { Logistics (for the patient, } \\
\text { medical, and global manage- } \\
\text { ment) }\end{array}$ & 52.9 & 46.8 \\
\hline$I_{2}$ & Consultation & NA & 23 & 23 \\
\hline$I_{3}$ & Care & $\begin{array}{l}\text { Actors (home and transporta- } \\
\text { tion) + Workload at patient } \\
\text { home }\end{array}$ & 170.3 & 275.9 \\
\hline$I_{4}$ & Waste disposal & Continuity of care & 6.1 & 7.7 \\
\hline
\end{tabular}

Table 23: Internal variable costs for each process and each pathology $\left(b_{i p}\right)$

\section{References}

E. Benzarti, E. Sahin, and Y. Dallery. Operations management applied to home care services: Analysis of the districting problem. Decision Support Systems, 55(2):587-598, 2013.

J. M. Borras, A. Sanchez-Hernandez, M. Navarro, M. Martinez, E. Mendez, J. L. L. Ponton, J. A. Espinas, and J. R. Germa. Compliance, satisfaction, and quality of life of patients with colorectal cancer receiving home chemotherapy or outpatient treatment: a randomised controlled trial. Bmj, 322(7290):826, 2001. URL http://www.bmj .com/content/322/7290/ 826. short.

L. Brotcorne, G. Laporte, and F. Semet. Ambulance location and relocation models. European journal of operational research, 147(3):451-463, 2003.

A. Caprara, P. Toth, and M. Fischetti. Algorithms for the set covering problem. Annals of Operations Research, 98(1):353?371, 2000. URL http://www.springerlink.com/index/ q5u70867336204hj.pdf.

J. Chataway, B. Porter, A. Riazi, D. Heaney, H. Watt, J. Hobart, and A. Thompson. Home versus outpatient administration of intravenous steroids for multiple-sclerosis relapses: a randomized controlled trial. American Journal of Ophthalmology, 142(3):565?571, September 2006. ISSN 0002-9394. doi: 10.1016/j.ajo.2006.07.009. URL http://www.sciencedirect.com/science/ article/B6VK5-4KRNG6N-1V/2/4fdadcd3625ff98f8e34bf996667a9ff.

K. Chevreul, L. Com-Ruelle, F. Midy, and V. Paris. The development of hospital care at home: an investigation of australian, canadian an british experiences. Technical report, Institut de Recherche et Documentation en Économie de la Santé (IRDES), 2005.

Christina Marsh Dalton and Patrick L. Warren. Cost versus control: Understanding ownership through outsourcing in hospitals. Journal of Health Economics, 48:1 - 15, 2016. ISSN 0167-6296. doi: http://dx.doi.org/10.1016/j.jhealeco.2016.02.003. URL http://www . sciencedirect.com/science/article/pii/S016762961600045X.

Paul R. Drake and Bethan M. Davies. Home care outsourcing strategy. Journal of Health Organization and Management, 20(3):175-193, 2006. doi: 10.1108/14777260610662726. URL https://doi.org/10.1108/14777260610662726. PMID: 16869353. 
D. J. Eaton, M. S. Daskin, D. Simmons, B. Bulloch, and G. Jansma. Determining emergency medical service vehicle deployment in austin, texas. Interfaces, page 96?108, 1985. URL http://www.jstor.org/stable/10.2307/25060655.

R. W. Floyd. Algorithm 97: Shortest path. Communications of the ACM, 5(6), 1962.

M. R. Garey and D. S. Johnson. Computers and intractability, volume 174 . Freeman San Francisco, CA, 1979. URL http://www.c.csce.kyushu-u.ac.jp/ makiyama/rinkou/ NPcomplete/NP_shiryou.pdf.

Edward L. Glaeser and Andrei Shleifer. Not-for-profit entrepreneurs. Journal of Public Economics, 81(1):99 - 115, 2001. ISSN 0047-2727. doi: http://dx.doi.org/10. 1016/S0047-2727(00)00130-4. URL http://www.sciencedirect.com/science/article/ pii/S0047272700001304

Cline Goulet, Hlne Gvry, Robert J. Gauthier, Linda Lepage, William Fraser, and Marilyn Aita. A controlled clinical trial of home care management versus hospital care management for preterm labour. International Journal of Nursing Studies, 38(3):259?269, June 2001. ISSN 0020-7489. doi: 10.1016/S0020-7489(00)00077-8. URL http://www.sciencedirect.com/ science/article/B6T7T-42H1RR4-3/2/7cd9bdea96a0baf747b10b3f2ff0bd8d.

Hongzhong Jia, Fernando Ordez, and Maged M. Dessouky. Solution approaches for facility location of medical supplies for large-scale emergencies. Computers $\& 3$ Industrial Engineering, 52(2):257-276, March 2007. ISSN 0360-8352. doi: 10.1016/j.cie.2006.12.007. URL http: //www.sciencedirect.com/science/article/pii/S0360835206002129.

Daniel P. Lorence and Amanda Spink. Healthcare information systems outsourcing. International Journal of Information Management, 24(2):131 - 145, 2004. ISSN 0268-4012. doi: http://dx.doi.org/10.1016/j.ijinfomgt.2003.12.011. URL http://www.sciencedirect.com/ science/article/pii/S0268401203001361.

Paolo Mariani, Rosa Falotico, and Biancamaria Zavanella. Outsourcing services in the italian national health service: The evaluation of private and public operators. Procedia Economics and Finance, 17:256 - 264, 2014. ISSN 2212-5671. doi: http://dx.doi.org/ 10.1016/S2212-5671(14)00872-7. URL http://www.sciencedirect.com/science/article/ pii/S2212567114008727. Innovation and Society - Statistical methods for the evaluation of services.

V. Marianov and D. Serra. Location problems in the public sector. In Facility Location: Applications and Theory, pages 119-143. Springer-Verlag, z. drezner \& H.W. hamacher edition, 2001. URL http://books.google.fr/books?hl=fr\&lr=\&id=sxpcsGN7K1YC\&oi= fnd\&pg=PA119\&dq=\%22location+problems+in+the+public+sector\%22\&ots=cKn6wjqH1r\& sig=1U68r3ftrtdPaVFJtAUq5t80csc

A. Matta, S. Chahed, E. Sahin, and Y. Dallery. Modelling home care organisations from an operations management perspective. Flexible Services and Manufacturing Journal, 26(3): 295-319, 2014.

Lawrence Nicholson, Asoo J. Vakharia, and S. Selcuk Erenguc. Outsourcing inventory management decisions in healthcare: Models and application. European Journal of Operational Research, 154(1):271 - 290, 2004. ISSN 0377-2217. doi: http://dx.doi.org/ 10.1016/S0377-2217(02)00700-2. URL http://www.sciencedirect.com/science/article/ pii/S0377221702007002 
D. Rischin, M. A White, J. P Matthews, G. C Toner, K. Watty, A. J Sulkowski, J. L Clarke, and L. Buchanan. A randomised crossover trial of chemotherapy in the home: patient preferences and cost analysis. Medical Journal of Australia, 173(3):125?127, 2000.

C. Rodríguez-Verjan, V. Augusto, X. Xie, and V. Buthion. Economic comparison between hospital at home and traditional hospitalization using a simulation-based approach. Journal of Enterprise Information Management, 26(1):135-153, 2012.

C. Rodríguez-Verjan, T. Garaix, X. Xie, and V. Augusto. Staff dimensioning in homecare services with uncertain demands. International Journal of Production Research, 53:7396-7410, 2015.

S. Shepperd, H. Doll, R. M Angus, M. J Clarke, S. Iliffe, L. Kalra, N. A Ricauda, V. Tibaldi, and A. D Wilson. Avoiding hospital admission through provision of hospital care at home: a systematic review and meta-analysis of individual patient data. Canadian Medical Association Journal, 180(2):175?180, 2009.

C. Toregas, R. Swain, C. ReVelle, and L. Bergman. The location of emergency service facilities. Operations Research, pages 1363-1373, 1971.

Nizar Triki, Thierry Garaix, and Xiaolan Xie. A two-phase approach for periodic home health care planning. In Automation Science and Engineering (CASE), 2014 IEEE International Conference on, pages 518-523. IEEE, 2014.

S. Yalcindag, A. Matta, and E. Sahin. Human resource scheduling and routing problem in home health care context: a literature review. In Proceedings of ORAHS 2011, 37th Conference on Operational Research Applied to Health Services, Cardiff, UK, 2011, 822, 2011. 